\title{
Discount rates of children and high school graduation
}

\author{
Marco Castillo*, Jeffrey L. Jordan**, Ragan Petrie* \\ *Department of Economics, Texas A\&M University, USA and Melbourne Institute, University of \\ Melbourne, Australia \\ Castillo: marco.castillo@tamu.edu, Petrie: rpetrie@tamu.edu \\ **Agricultural and Applied Economics, University of Georgia, USA \\ Jordan: jjordan@uga.edu
}

December 8, 2017

\begin{abstract}
We present direct evidence that children who are unwilling to wait for a larger reward and instead prefer a small one earlier (i.e. they have a higher discount rate) are less likely to graduate from high school. Using an incentivized experiment to measure the discount rates of 878 children, we find large effects on human capital accumulation - a one standard deviation increase in the discount rate decreases the probability of graduating from high school by four percentage points. Importantly, the impact of a child's discount rate is distinct from behavioral problems (e.g. disciplinary referrals), academic achievement, risk attitudes, demographics and household environment. Consistent with the existence of nonpecuniary costs to finishing high school, impatient children with poor academic achievement are significantly less likely to graduate than impatient children with high achievement.
\end{abstract}

JEL codes: I26, J24, D90, C91

Keywords: high school graduation, discount rates, economic experiments 


\section{Introduction}

Roughly one in five high school students nationwide do not graduate on time, and the dropout rate is higher for boys and black and hispanic students (NCES, 2014). Not completing high school has a large effect on earnings - dropouts can expect to earn $\$ 10,000$ less per year than a high school graduate and $\$ 36,000$ less than a college graduate (U.S. Census). ${ }^{1}$ Obtaining a GED (general equivalency degree) in lieu of a high school diploma does not necessarily obviate the decrease in earnings. Conditional on cognitive ability, individuals with a GED earn less than dropouts (Heckman and Rubinstein, 2001). In addition to higher earnings, schooling has positive effects on other outcomes as well. Students who experience an extra year of compulsory education are less likely to report being in poor health, unemployed, and unhappy (Oreopoulos, 2007).

Given this evidence, it is puzzling that a significant proportion of the population does not finish high school (Heckman and LaFontaine, 2010; Murnane, 2013). Several authors have suggested that this might be due to the presence of non-pecuniary costs to schooling and large differences in discount rates (Heckman, Lochner, and Todd, 2003; Lang and Ruud, 1986; Murnane, 2013; Oreopoulos, 2007), and Eckstein and Wolpin (1999) present evidence consistent with this hypothesis. ${ }^{2}$ An individual's discount rate represents the willingness to trade off smaller, early rewards (e.g. spending time playing with friends) for larger, later rewards (e.g. passing classes and graduating from high school). Higher discount rates indicate an individual is less willing to wait. We note that ex-ante it is impossible to know whether human capital accumulation or unobserved non-pecuniary costs to human capital accumulation explain high school graduation. As we show in the theory section, they have similar predictions. Our study demonstrates that experimental methods might alleviate this identification problem by measuring preferences directly. ${ }^{3}$

While an individual's discount rate is theoretically related to schooling investment decisions and the existing empirical literature strongly hints at this, the supportive evidence is indirect. For instance, a child's discount rate has been linked to future disciplinary referrals (Alan and Ertac, forthcoming; Castillo, Ferraro, Jordan, and Petrie, 2011) and misbehavior in school (Sutter, Kocher, Glaetzle-Ruetzler, and Trautmann, 2013), and disciplinary referrals have been shown to predict high school graduation (Alexander, Entwisle, and Horsey,

\footnotetext{
${ }^{1}$ Recent research on the effects of compulsory education (Oreopoulos, 2006, 2007) shows large positive effects on income of acquiring one extra year of schooling, with increases of 10 to 14 percent. Indeed, the returns to high school graduation might even be larger than previously thought once some of the assumptions in the estimated wage equation are relaxed (Heckman, Lochner, and Todd, 2003).

${ }^{2}$ Using data from the Panel Study of Income Dynamics (PSID), these authors estimate a structural model showing that children who drop out of high school have lower abilities, lower expectations of the returns to education and higher returns to working while attending high school.

${ }^{3}$ We also discuss the potential effect of risk preferences on behavior. The effect of risk attitudes on behavior is more difficult to sign. While risk aversion deters human capital accumulation, it might also have a positive effect if it prevents a child from getting into trouble in the short-run. Its impact is therefore indeterminate.
} 
1997; Rumberger, 1995). In this paper, we provide evidence of a direct link between higher discount rates and a lower probability of graduating from high school. We collect an incentivized experimental measure of the discount rate from children in 8th grade and test whether it predicts on-time high school graduation five years later. ${ }^{4}$

To measure the discount rate, children are asked to make choices between receiving a fixed amount of money in 1-month and a larger amount of money in 7-months. Choices are incentivized with monetary payment, and the front-end delay design we use has several advantages for measuring a child's discount rate. First, by delaying all payments into the future, we eliminate potential confounds due to mistrust that non-immediate payments will be made. Second, the procedure is incentive-compatible and expected to reveal true underlying preferences under standard assumptions. Third, individual discount rates can be measured even if the individual has quasi-hyperbolic preferences or exhibits impulsivity. ${ }^{5}$ These design advantages address several of the methodological issues that have been shown to influence the measurement of time preferences in adults (Andreoni and Sprenger, 2012) and are likely to be issues with children as well.

Prior studies have shown a relationship between present-biasedness and/or impulsivity and labor market outcomes (Cadena and Keys, 2015; DellaVigna and Paserman, 2005; Mischel, Shoda, and Rodriguez, 1989). ${ }^{6}$ Our findings provide support for a relationship between an experimental measure of an individual's discount rate and the willingness to invest in human capital. Uncovering an independent effect of the discount rate is important because it hints at the significance of both perceived returns to education and non-pecuniary costs to human capital accumulation. Discount rates and short-term behavioral problems are conceptually different and could have independent effects. Interventions aimed at improving self-control may have little effect on children who put a low value on future returns to education.

We have two main results. First, higher individual discount rates are correlated with a lower probability of graduating from high school in four years. The estimated difference in graduation rates between the most impatient and most patient child is at least 8 percentage points. This holds controlling for the child's age, sex, race, behavioral problems (e.g. disciplinary referrals), academic achievement and whether the child is eligible for free or reduced price meals (a proxy for income) or is in a special or gifted education program. Second, consistent with the existence of heterogeneous non-pecuniary costs to studying, a higher discount rate is particularly costly for those children with low academic achievement.

\footnotetext{
${ }^{4}$ The experimental measure we use is theoretically motivated (Harrison, Lau, and Williams, 2002) and empirically validated (Castillo, Ferraro, Jordan, and Petrie, 2011; Sutter, Kocher, Glaetzle-Ruetzler, and Trautmann, 2013).

${ }^{5}$ To keep the experiment simple, we did not present the children with tasks that would have allowed us to measure quasi-hyperbolic preferences. Individuals with quasi-hyperbolic preferences behave as exponential discounters when comparing streams of consumption occurring strictly in the future. The front-end delay design we use identifies a discount rate separately from a present-biasedness parameter.

${ }^{6}$ Golsteyn, Gronqvist, and Lindahl (2014) look at the effects of impatience on labor market outcomes. The impatience measure does not distinguish between between present-biasedness and discounting.
} 
Impatient children who are not performing well academically are less likely to graduate high school than equivalently impatient, but high-performing, children. Our findings highlight the importance of academic achievement in middle school on future graduation rates (see also Murnane (2013)) and the heterogeneous effect of discount rates on behavior. ${ }^{7}$ How well a child has performed in primary and middle school is likely to be related not only to cognitive ability but also to underlying preferences (see also Almlund, Duckworth, Heckman, and Kautz (2011)).

Several robustness checks on the relationship between discount rates and high school graduation confirm our main results. We continue to find a strong relationship when we relax the assumptions that the discount rate is observed precisely and that the relationship with high school graduation is linear. Checks include not treating the discount rate as an interval variable and accounting for risk attitudes. Regarding the latter, it is known (e.g. Andersen, Harrison, Lau, and Rutstrom (2008)) that discount rates can be mismeasured if agents are not risk neutral. We supplement our analysis with additional data on risk preferences from a subsample of the children who participated in our time preference experiment to test if risk attitudes might explain our results. Once we account for risk attitudes in the estimations, the negative effect of a higher discount rate on high school graduation remains large and significant.

Many factors may drive the correlation we find between discount rates and high school graduation. We explore this further by collecting survey data from parents on barriers to high school graduation in a subsample of households. We find that low parental expectations of a child's ability to graduate from high school, having a sibling that dropped out of high school, frequent relocation of residence, living in a credit constrained household and having a previously-incarcerated family member are strongly correlated with the failure to graduate from high school. These variables, however, are not correlated with a child's individual discount rate. This provides support that our main findings are not due to an omitted variable problem. We also confirm that disciplinary referrals are correlated with a child's self-reported impulsive behavior. By accounting for these behavioral problems in our main analysis, we show that a child's discount rate has a separate effect on high school graduation.

Our study adds to the few longitudinal studies on the economic preferences of children and introduces an experimental measure of the discount rate to predict future field behavior. Mischel et al. (1989) show that a child's ability to delay immediate consumption at age four predicts social and cognitive competency during adolescence as well as the ability to deal with stress and frustration (see also Mischel, Shoda, and Peake (1988); Shoda, Mischel, and Peake (1990)). The children in our experiments were asked to choose between quantities that were in the future, so we do not have an experimental measure of impulse-control

\footnotetext{
${ }^{7}$ Several studies suggest that heterogeneity in preferences is an important determinant of labor market outcomes (Barsky, Juster, Kimball, and Shapiro, 1997; Bonin, Dohmen, Falk, Huffman, and Sunde, 2007; Burks, Carpenter, Goette, and Rustichini, 2009; Chabris, Laibson, Morris, Schuldt, and Taubinsky, 2008; Kimball, Sahm, and Shapiro, 2008; Meier and Sprenger, 2010).
} 
or present-biasedness. The supporting survey evidence we have, however, suggests that a child's discount rate is separate from present-biasedness.

Additional studies have obtained measures of self-control and economic preferences early in life to examine outcomes as adults. Moffitt, Arseneault, Belsky, Dickson, Hancox, Harrington, Houts, Poulton, Roberts, Ross, Sears, Thomson, and Caspi (2011) use panel data from 1,000 New Zealanders to show that self-control during the first decade of life correlates with better health outcomes, more wealth and lower participation in crime. ${ }^{8}$ Golsteyn et al. (2014) correlate delayed consumption choices made as a teenager in a large panel in Sweden with educational attainment, income level and health outcomes. ${ }^{9}$

We combine our theoretically-grounded measure of the discount rate of a child with supplemental data on academic achievement, behavioral problems, demographics and household environment to estimate the direct effect of the discount rate on high school graduation. Our findings provide evidence that patience is indeed linked to educational success and complement recent research on educational interventions that show promising evidence of early interventions on developing non-cognitive skills (Alan, Boneva, and Ertac, 2015; Gertler, Heckman, Pinto, Zanolini, Vermeersch, Walker, Chang, and Grantham-Zmcgregor, 2013; Heckman, Pinto, and Savelyev, 2013; Heckman, Stixrud, and Urzua, 2006).

The paper is organized as follows. Section 2 presents a simple model of the decision to complete high school. Section 3 describes the study setting, and experimental design. Section 4 describes the data used in the analysis. Section 5 presents the main results and robustness checks. Section 6 concludes.

\section{A Simple Model}

In this section we present a simple model of the decision to finish high school. It is an extension of Oreopoulos (2007) in which we consider the possibility that children engage in risky activities that might affect their future wages. The model and its predictions will help guide our understanding of some of the empirical results presented in the paper.

A child must choose between finishing high school $(S=1)$ or not $(S=0)$ and between behaving $(B=1)$ or not $(B=0)$. The lifetime utility over $T$ periods is:

$$
V(S)=u\left(c_{0}\right)-\phi(S, B)+\sum_{t=1}^{t=T}(1+d)^{-t} u\left(c_{t}\right)
$$

\footnotetext{
${ }^{8}$ Self-control is measured by a composite index of self-reports and reports by parents and teachers on observed behavior and thus reflects a mix of preferences and constraints faced by the child. Impatient children might differ in the opportunity cost of their time and/or on the strategies they use during interactions with other children and adults.

${ }^{9}$ Decisions were made over a hypothetical amount of money to be received immediately and a larger amount of money to be received in 5 years. Most (incentivized) experiments measuring time preferences have delays of 0-7 months. This is typically done for practical reasons and provides a shorter time frame for future payment. One exception is Harrison et al. (2002) who elicit responses from adults over time periods as long as 3 years.
} 
The term $u\left(c_{0}\right)-\phi(S, B)$ accounts for the utility of consumption in period 0 and a non-pecuniary cost associated with choice $S$ and $B$. Both studying and behaving are costly. That is, $\phi(1, B)>\phi(0, B), B=0,1$ and $\phi(S, 1)>\phi(S, 0), S=0,1 .^{10}$ For a discount rate, $d$, the last term of the equation represents the geometrically discounted utility of consumption for time separable preferences over consumption. In our study, we measure parameter $d$ with economic experiments. The curvature of the utility function $u$ captures the child's risk attitudes.

The corresponding intertemporal budget constraint for an interest rate $r$ is the following, where $y_{t}(S, 1)$ is the income level at education level $S$ and behavior $B=1$ :

$$
\sum_{t=0}^{t=T}(1+r)^{-t} c_{t}=\sum_{t=0}^{t=T}(1+r)^{-t} y_{t}(S, 1)
$$

If instead behavior is $B=0$, the intertemporal budget constraint depends on the realization of a random variable $\omega \in\{\underline{\omega}, \bar{\omega}\}$ with $\operatorname{Pr}(\omega=\underline{\omega})=p$.

$$
\sum_{t=0}^{t=T}(1+r)^{-t} c_{t}=\sum_{t=0}^{t=T}(1+r)^{-t} y_{t}(S, 0)+1[\omega=\bar{\omega}] \pi-1[\omega=\underline{\omega}] \eta
$$

In equation (3), $\pi(\pi>0)$ is a one-time payoff to be received in period 0 if $\omega=$ $\bar{\omega}$ and $\eta(\eta>0)$ is a one-time loss to be incurred in period 0 if $\omega=\underline{\omega}$. These terms represent the short-term appeal of misbehavior and are analogous to the non-pecuniary cost of education and good behavior. In this set-up we allow for income streams to be affected by both education levels and behavior during school years. That is, we explicitly model the possibility that the market rewards behavioral traits. We also consider the possibility that (mis)behavior might produce random outcomes in the short run. We will have that the willingness of a child to behave $(B=1)$ will depend on the alternative streams of possible payoffs and his risk attitudes.

Given that our simple model only allows for two educational outcomes (finishing high school or not) and two behavior outcomes (behave or not), we assume that $\phi(0,0)=0$. We also assume that the realization of random variable $\omega$ occurs prior to the realization of income but after the decisions to study and behave have been made. That is, the decision to behave is irreversible.

The first order conditions associated with the intertemporal problem outlined above produce the conditions which determine whether a child finishes high school or not. Specifically, a child will not finish high school conditional on behaving $(B=1)$ when the following expression holds:

\footnotetext{
${ }^{10}$ These costs could be affected by the child's innate ability as well. We do not explicitly model this possibility here.
} 


$$
\left[y_{0}(0,1)-y_{0}(1,1)\right]+\frac{(1+d)^{t}}{(1+r)^{t}} \frac{\phi(1,1)-\phi(0,1)}{u^{\prime}\left(c_{t}\right)}-\sum_{t=1}^{t=T}(1+r)^{-t}\left[y_{t}(1,1)-y_{t}(0,1)\right]>0
$$

The first term of equation (4) accounts for the additional income that could be obtained by not completing high school. ${ }^{11}$ This would imply that, for the type of jobs available to teenagers, $\left[y_{0}(0)-y_{0}(1)\right]$ might be negatively correlated with a child's ability to succeed at school. The second term captures the effect of non-pecuniary costs to studying on the decision to not finish high school. The term shows that, conditional on the non-pecuniary cost of school, more impatient children (higher $d$ 's) are more likely to drop out. The last term is the present value of the income that a child would obtain if he finished high school. If wages are increasing in the cognitive and non-cognitive abilities of the child, conditional on the level of education and market interest rates, this term would depend also on measures of these abilities.

The necessary condition for the decision to drop out of school conditional on not behaving $(B=0)$ is slightly more complicated due to the effect of random streams of income. A child will not finish high school if the following holds:

$$
\begin{aligned}
{\left[y_{0}(0,0)-y_{0}(1,0)\right] } & +\frac{(1+d)^{t}}{(1+r)^{t}} \frac{\phi(1,0)}{(1-p) u^{\prime}\left(\bar{c}_{t}\right)+p u^{\prime}\left(\underline{c}_{t}\right)} \\
& +\frac{(1-p) u^{\prime}\left(\bar{c}_{t}\right) \pi-p u^{\prime}\left(\underline{c}_{t}\right) \eta}{(1-p) u^{\prime}\left(\bar{c}_{t}\right)+p u^{\prime}\left(\underline{c}_{t}\right)}-\sum_{t=1}^{t=T}(1+r)^{-t}\left[y_{t}(1,0)-y_{t}(0,0)\right]>0
\end{aligned}
$$

The first term of equation (5) accounts for the certain short term additional income due to not completing high school. The second term accounts for the non-pecuniary cost to studying. In this term, the marginal utility of consumption is replaced by the expected marginal utility of consumption. When $\omega=\bar{\omega}$ consumption equals $\bar{c}_{t}$ and when $\omega=\underline{\omega}$ consumption equals $\underline{c}_{t}$. Again, more impatient children are more likely to not finish high school. The third term accounts for random outcomes in the first period. Since when $\omega=\bar{\omega}$ there is an income gain $(\pi)$ and when $\omega=\underline{\omega}$ there is an income loss $(\eta)$, we have that $\forall t: \bar{c}_{t} \geq \underline{c}_{t}$. This is due to the fact that consumption decisions are made after $\omega$ is realized and $\pi(\eta)$ has a positive (negative) income effect. This implies that the third term will be decreasing in the child's level of risk aversion. ${ }^{12}$

In other words, the third term says that a relatively more risk averse child should both be less likely to misbehave, but conditional on misbehaving be less likely to drop out of school. Note that we would normally expect risk aversion to have a negative effect on graduation if

\footnotetext{
${ }^{11}$ Indeed, empirical evidence suggests that this differential income is larger for those that do drop out relative to those who remain in school (Eckstein and Wolpin (1999)).

${ }^{12}$ The term $\frac{u^{\prime}\left(\bar{c}_{t}\right)}{u^{\prime}\left(\underline{c}_{t}\right)}$ is less than 1 and decreasing in risk aversion.
} 
the payoffs associated with having a high school diploma are more variable in the future. In this model, we consider the possibility that risk aversion deters misbehavior if misbehavior has attractive, but risky, payoffs contemporaneous with human capital accumulation. This is a plausible consideration. A result frequently discussed in the economics literature on crime (e.g. Freeman (1999)) is that risk aversion can help to reduce crime. The last term in equation (5) is the present value of the income that a child would obtain if he finished high school but misbehaved $(B=0)$.

In sum, the simple model shows that a higher discount rate is correlated with a higher likelihood of not graduating from high school. It also shows that the effect of risk attitudes on the decision to dropout of high school depends on the short and long-run returns to misbehaving. With the existence of immediate rewards to behaving now, a risk-averse individual will be more likely to behave and more likely to finish high school. We will present empirical evidence consistent with these predictions.

Note that the model presented above can be modified to make the connection between graduation and misbehavior more direct - income streams depend on both the decision to finish high school and behavior during high school. For instance, by making $\eta$ depend on the education level chosen, $S$, then $\eta(1)=\sum_{t=0}^{t=T}(1+r)^{-t}\left(y_{t}(1,0)-y_{t}(0,0)\right)$ and $\eta(0)=\eta$, then the model illustrates the possibility that misbehavior carries the risk of losing the benefits of completing high school. The assumption that risky behavior produces only short-term uncertainty is included to demonstrate that risk aversion can have a direct and positive impact on graduation. A negative relationship between risk aversion and human capital accumulation is expected if the returns to education are uncertain and also because risk aversion mimics discounting (e.g Andersen et al. (2008)). As noted by (Oreopoulos, 2007), a model with uncertainty and no short-term rewards to misbehavior will predict that relatively more impatient and more risk averse children will be less likely to graduate. The model we present here brings insights from the economic theory of crime (Freeman, 1999) to better understand observed patterns in the data.

The model also makes clear that the existence of non-pecuniary costs to human capital accumulation resemble those of preferences. Children could either be more impatient or they may face higher non-pecuniary costs (e.g Eckstein and Wolpin (1999)). This identification problem can be resolved by collecting data on preferences (see also Murnane (2013)).

\section{$3 \quad$ Study setting and design}

The setting for our study is a suburban/rural county school district in Georgia. ${ }^{13}$ The district is typical of suburban/rural school districts in the U.S. in that income and education levels are lower compared to urban areas. For example, 2011 per capita income in the district was $\$ 28,305$ (\$36,979 in Georgia). According to the Georgia Department of Education, 69.2

\footnotetext{
${ }^{13}$ The study site is the same as in Castillo, Ferraro, Jordan, and Petrie (2011).
} 
percent of students in the district graduated in four years as of 2015. ${ }^{14}$ Our experiment was conducted in 8th grades classes at all four public middle schools in the district, and our sample represents $82 \%$ of the entire student population. The students in our sample come from a broad range of socio-economic backgrounds (sample statistics are presented in Table 1). At the time of the experiment, $96 \%$ of our participants were 13 or 14 years old (mean=13.80, $\mathrm{SD}=0.56$ ). In Georgia, students can make the decision to drop out of high school at the age of 16 . Thus, we experimentally measure discount rates in the period prior to when this important decision could be made.

\subsection{Experimental design}

We measure time preferences by eliciting discount rates with the front-end delay design used by Harrison, Lau, and Williams (2002). Instead of allowing an option of payment immediately after the experiment, both payments are delayed. This design mitigates the potential for confounding trust and patience in the experiment and makes the transaction costs of receiving payment across options the same. In our experiment, participants are asked, orally and in writing, to make twenty decisions in total. For each decision, participants must choose whether they would prefer $\$ 49$ in one month or $\$ 49+\$ \mathrm{X}$ in seven months. The amount of money, $\$ \mathrm{X}$, is strictly positive, increases over the twenty decisions and is chosen such that the implied discount rate for choosing $\$ 49+\$ \mathrm{X}$ over $\$ 49$ increases at a constant rate of $7.35 \%$. Table 2 shows the decisions that participants are asked to make. ${ }^{15}$ For example, in the first decision, a participant is asked if she would prefer $\$ 49$ one month from now or $\$ 50.83$ seven months from now. In the ninth decision, a participant is asked if she would prefer $\$ 49$ in one month or $\$ 67.61$ in seven months. Participants are asked to make one choice for each of the twenty decisions on the decision sheet. Based on discussions with teachers and students at other schools, we determined that the range of $\$ 50$ to $\$ 99$ would be considered by adolescents to be "large" payoffs, but not so large as to potentially cause problems with their parents. In addition, the time frame for decisions, one month and seven months, was chosen to reflect the longer-run decisions children might face, such as finishing high school, but also be within the school year so that payment would be received prior to moving on to high school the following year.

If participants have access to financial opportunities and behave in a way consistent with consumption smoothing, our experimental protocol may only reveal the interest rates available to participants. ${ }^{16}$ Our discussions with teachers at the study site and with similar aged students at other schools assure us that the children in our study do not face these type

\footnotetext{
${ }^{14}$ See http://www.gadoe.org/External-Affairs-and-Policy/communications/ Pages/PressReleaseDetails.aspx.

${ }^{15}$ Participants did not see the last column indicating the implied annual interest rate.

${ }^{16}$ Under the conditions of access to credit markets and consumption smoothing, Cubitt and Read (2007) suggest that economic experiments using money incentives to measure discount rates are unlikely to reveal the true discount rate of the participants.
} 
of financial opportunities. Also, empirical evidence suggests that consumption smoothing is imperfect (Johnson, Parker, and Souleles, 2006; Parker, Souleles, Johnson, and McClelland, 2013). It is unlikely that middle school students smooth consumption, especially in the case of a small transfer (see Halevy (2014) for a thoughtful argument along these lines). Experiments with low, but meaningful, stakes such as ours are on good footing to reveal a measure of an individual's discount rate.

Economic theories of discounting predict that an individual faced with the decisions in Table 2 would either choose (a) \$49 for all decisions, (b) the higher payment for all decisions, or (c) $\$ 49$ for a number of decisions starting with Decision 1 and then switch to the higher payment for the remaining decisions. In other words, if an individual chose to receive $\$ Y$ in seven months rather than $\$ 49$ in one month, then the individual will prefer any amount $\$ Z>\$ Y$ in seven months rather than $\$ 49$ in one month. The point at which an individual switches to the higher, but later, payment indicates the range in which an individual's discount rate lies. We chose the later payments so that the range is always a fixed width. This design feature will be used in our data analysis to test the robustness of our main results to the construction of the discount rate measure.

Following Harrison, Lau, and Williams (2002), we call the participants who make choices consistent with the patterns of (a)-(c) to be "consistent" decision-makers. However, in experiments using decision sheets like the one in Table 2, some participants are "inconsistent" decision-makers: they choose $\$ Y$ in seven months rather than $\$ 49$ in one month, but then choose $\$ 49$ in one month rather than $\$ Z>\$ Y$ in seven months. Harrison, Lau, and Williams (2002) and Meier and Sprenger (2010) found that 4\% and 11\%, respectively, of their adult participants were inconsistent in their choices. Bettinger and Slonim (2007), whose participants were between 5 and 16 years old, found that $34 \%$ of their sample were inconsistent. The proportion of inconsistent decision-makers in our sample (31\%) is closer to that of Bettinger and Slonim (2007).

In the data analysis, we have various ways in which we construct the discount rate measure for inconsistent participants. This is discussed in detail in the Data section. We test the robustness of these measures and control for whether or not the participant is inconsistent in our regression analysis. All discount rate measures produce similar results, and being inconsistent is never found to be significant.

\subsection{Experimental implementation}

In each session, participants are assigned a unique identification code. This code is private, and participants do not know the identification codes of other participants. Participants make their decisions by circling one amount, either $\$ 49$ or $\$ 49+\$ \mathrm{X}$, on their decision sheet for each of the twenty decisions. After completing their decisions, each participant puts her decision sheet in an envelope and the envelopes are collected.

One decision out of the twenty decisions is randomly chosen for payment by taking 
20 index cards with the numbers 1-20 written on them, shuffling them in front of the participants, presenting them "face down," and asking a participant to choose one card. The number on the card is the decision number to be paid for each of the three participants in each session who are chosen to receive payment. So, for example, if decision 15 is chosen for payment and one of the winning participants circled $\$ 83.03$, the participant would receive $\$ 83.03$ in seven months. If another winning participant circled $\$ 49$, that participant would receive $\$ 49$ in one month.

After determining the decision to be paid, all the envelopes are shuffled in front of the participants, and three envelopes per session are chosen for payment. The identification codes of those chosen to receive payment are written on the blackboard. Because identification codes are kept private by each participant, no one knows which participants have been chosen to receive payment. Those who are chosen to receive payment are paid with a Walmart gift card by the school principal on the specific date for the decision chosen. We chose to pay with a Walmart gift card for two reasons. It minimizes potential problems associated with giving children cash and it can be transformed into many goods that children desire, so it very similar to cash. We chose to have the school administration store and distribute the cards to assure the children that they would be paid in the future. In all schools, the principal is regarded as a permanent fixture and interacts regularly with the children. On or within a week of the payment date, the participants go privately to the principal's office to pick up their gift cards. If a child moves out of the district before the time of payment, the child is found and given the gift card. Names and payments are kept private. Participants know all of these procedures before making their decisions.

All experiments were conducted by the authors, and 878 8th grade students participated (ages 13 to 15). One hundred and twenty children were paid an average of $\$ 62.88$ (std dev $=\$ 18.04$ ), with a total payout of $\$ 7,546.17$. One month after the experiment, 66 children received gift cards of $\$ 49$. Seven months after the experiment, 54 children received gift cards ranging from $\$ 52.71$ to $\$ 98.02$. All children who were randomly chosen to be paid did receive payment. The experiments were conducted in three rounds of data collection and encompass all four middle schools in the school district. The first round was on September 19, 2006. The second was on August 31, 2007, and the third was on August 26, 2008.

\section{Data}

In this section, we discuss and define the discount rate measure, our outcome measure for high school graduation and additional data used as controls in the analysis.

\subsection{Discount rate measure}

As noted earlier, most children were consistent in their decisions, and if they switched to the later payment, they did so only once and stayed there. Some $31 \%$ were inconsistent 
and switched more than once. ${ }^{17}$ For consistent children, we use their unique switch point to determine the discount rate.

For inconsistent children, we use four different approaches to determine the discount rate: (1) the first switch point, (2) the last switch, (3) the average of all the discount rates that minimize the number of switches, and (4) a nonparametric approach to find the unique switch point that minimizes the cost to move a child's choices so that they are then consistent. This last measure is constructed by calculating the monetary loss in payoffs to change decisions to all possible consistent choice patterns and choosing the one that minimizes the loss. ${ }^{18}$

The discount rate value assigned to the child is the midpoint of the 7.35 range associated with the unique switch. So, for example, if a child switches to the later payment at the 11th decision, the discount rate is 77.18 (midpoint of $[73.50,80.85]$ ). Using the midpoint of the range, rather than the lower or upper end, avoids values of zero or infinity. For those who chose all late or all early payments, we assign them a value of 3.68 and 143.32 respectively. In our design, discount rates fall in 20 equally spaced 7.35 percentage points ranges, and this reduces the possibility that they artificially accumulate at one particular value. It is known that using mid-points when an independent variable is an interval can produce biased results (Hsiao, 1983; Manski and Tamer, 2002), so we show in the Robustness section that the results are similar or stronger if we treat discount rates as interval data. ${ }^{19}$

The discount rate measure is constant for consistent children, and the inconsistent children have four measures. In our analysis, we test the robustness of our four approaches to measuring discount rates on high school graduation and find similar results. Our main results include all children whose cost to make the discount rate consistent is in the lower 95 percentile. Results using the data from all children are similar but less precise in some specifications. $^{20}$

Our discount rate measure is based on decisions made almost five full years prior to the final date for an on-time high school graduation. Decisions made in the experiment could be correlated with the determinants of high school graduation if, for instance, those who are likely to dropout because of family issues perceive the future as more uncertain and act more impatiently in the experiment (Halevy, 2008; Saito, 2011). ${ }^{21}$ While we did not collect data in the experiment on this possibility, we do address this in the analysis by including controls

\footnotetext{
${ }^{17} 5.58 \%$ of participants switched two times, $4.56 \%$ switched three times, and $20.62 \%$ switched four or more times.

${ }^{18}$ This is the same procedure as was used in Castillo et al (2011). It calculates the absolute distance between the actual amount chosen and the amount that a consistent person would have chosen. It then assigns the discount rate corresponding to the consistent pattern that minimizes this distance.

${ }^{19}$ Table A6 in the Appendix shows these results. We estimate the effect of each possible discount rate range using dummy variables and test for the their joint significance. The results remain significant and the relationship between discount rates and high school graduation is similar to that obtained using midpoints and a linear relationship.

${ }^{20}$ Table A3 in the Appendix shows these results.

${ }^{21}$ We note that our experimental design mitigates payment uncertainty, and all participants chosen to be paid did receive their Walmart gift card in one or seven months.
} 
for differences in background that are contemporaneous to the experiment and are likely to be correlated with the probability of a timely graduation (e.g. family wealth, family structure). Our results are robust, and this gives us confidence that the significant and negative relationship we uncover between a child's discount rate and high school graduation is not spurious.

\subsection{Background data}

We collected data from the school district on demographics of the children (e.g. sex, race, age), test scores in 7th and 8th grade (e.g. reading, math, social studies and science), whether or not the child was eligible for free and reduced meals and whether the child was in a special education or gifted program. To keep the experiment short and reduce the burden on the children, teachers and school administration, we did not administer additional surveys or tests, so we do not have measures of IQ or personality traits. Our measure of academic achievement is constructed by extracting a common factor from the 7 th grade standardized test scores in reading, math, social studies and science. There is only one common factor underlying these variables. ${ }^{22}$ We test for the robustness of our results if we instead replace the common factor by the four test scores separately and find similar results.

To obtain measures of housing valuations and home ownership, we matched the children's addresses with the district's tax records. Information on household characteristics was obtained from a phone survey with parents on a subsample of 303 households. The survey collected background information on educational attainment of the parents, family structure, credit and borrowing history, whether or not the household faced relocation or criminal problems, parents' expectations on whether or not the child would graduate high school and failure of siblings to complete high school. ${ }^{23}$ Perceptions of school and its value to the child were collected with a survey given to a subsample of 134 children. Finally, children in the 2008 cohort of the experimental study answered a short questionnaire with questions regarding educational status of the parents and family structure. Information from these three surveys and the census track data are used to construct controls for the regression analysis.

\subsection{High school graduation and attrition}

The current definition for an on-time graduation by the state of Georgia (see www.gadoe.gov) is completing all requirements for high school in four years, and this is commonly used in

\footnotetext{
${ }^{22}$ If the 7 th grade score is missing, we replace it with the score in the 8 th grade. The scores are rescaled to reflect a change in the scoring of the test between 2006 and 2007. Figure A1 in the Appendix shows Horn (1965)'s parallel factor analysis. The Cronbach alpha scale reliability coefficient of the test scores is 0.7993.

${ }^{23}$ The sample of eligible households for the survey was 630 . Of these, 303 responded to the survey, 117 refused to respond and 210 could not be reached for various reasons.
} 
the education literature (Murnane, 2013). Data on high school graduation status was provided by the school district administration, however, there is no information for about 30 percent of the children who participated in the experiment. These children transferred to other schools outside the district or dropped out of the system. ${ }^{24}$ So, we cannot determine with certainty if they finished high school in four years or not.

Table 3 provides evidence of the differences between children for whom we have graduation outcomes and those for whom graduation outcomes are missing. This table illustrates that children who attrited from the sample are different and display signs that they may have difficulty graduating from high school. For example, children with missing graduation outcomes have more disciplinary referrals in 7 th grade, have lower academic achievement in 8th grade, are more likely to receive free and reduced price meals, are more likely to be in special education, have accumulated fewer credits two years after the experiment, have parents with lower levels of education and live in a household that is less likely to respond to requests to complete a survey. These results are confirmed with a Probit regression of the probability that a child's graduation outcome is observed on a variety of covariates (Table A1 in the Appendix).

Our approach to handling this missing information is to correct for attrition by reweighting observations according to the inverse of the probability of the outcome being observed (Wooldridge, 2010). We use the data on the children for whom we observe graduation status and then reweight the observations based on the estimates in Table A1. Our main findings are robust to an alternative approach of imputing these missing data. This alternative is discussed in Section 5.4.

\section{Results}

\subsection{Discount rates}

The distributions of the four discount rate measures we construct (average switch, first switch, last switch, min cost) are shown in Figure 1. There is a large amount of heterogeneity, and the discount rates span the full range of possible values. The pairwise correlations across the measures are significant and strong and range from 0.82 to $0.96 .{ }^{25}$ Roughly $16 \%$ of children have discount rates less than $20 \%$, and $36 \%$ of children have discount rates in excess of $100 \% .^{26}$

\footnotetext{
${ }^{24}$ Of the children who participated in the experiment, $58.0 \%$ are confirmed to have graduated in four years, $9.8 \%$ are confirmed to have "dropped out" (e.g. due to being expelled, lack of attendance, still enrolled in high school, incarcerated, low grades/school failure), and the remaining $32.2 \%$ have an uncertain graduation status.

${ }^{25}$ The pairwise correlation between average switch and first switch is 0.9646 , last switch is 0.9627 , and min cost is 0.9215 . The correlation between first and last switch is 0.8587 and min cost is 0.8197 . The correlation between last switch and min cost is 0.9597 .

${ }^{26}$ This excludes the 5 percent of children that have no discernible pattern of behavior.
} 


\subsection{High school graduation}

We assess the relationship between high school graduation and a child's discount rate using Probit regression analysis. The regression specification includes covariates to control for the child's academic achievement, past behavioral problems, demographic characteristics of the child, household environment and parental background. Attrition in the dependent variable (high school graduation status is unknown) is accounted for by using inverse probability weighting based on the regression reported in Table A1.

Table 4 reports the marginal effects of the probability of graduating high school on one of the discount rate measures (average switch, first switch, last switch or min cost) and covariates. All specifications show significant effects of the discount rate, disciplinary referrals in 7th grade, higher academic achievement in 8th grade, age, sex, race, and eligibility for free or reduced price meals on high school graduation. ${ }^{27}$ A 100 percentage point increase in the discount rate decreases the probability of graduating from high school between 7.9 to 9.1 percent depending on the specification of the model. These effects are similar to those of being male (about 8 percent). Given that historically about 28 percent of the children in the study district do not graduate high school on time and the marginal effects of the discount rate are between 8-9 percentage points, this implies that discount rates could explain up to one-third of the graduation gap.

Our main result is that more impatient children are less likely to graduate from high school, even controlling for demographics, past behavioral problems, household characteristics and academic achievement. This is robust to several ways of measuring the discount rate. Given that our measure of time preferences is constructed to be separate from presentbiasedness and our results are robust to the inclusion of behavioral measures, these findings suggests that discount rates have an independent effect on human capital accumulation.

\subsection{High school graduation accounting for risk preferences}

The results thus far have established an independent effect of impatience on high school graduation under the assumption of risk neutral preferences. If instead children are risk averse, and this is not accounted for in the analysis, we could overestimate the effect of the discount rate on graduation.

We have two approaches to address this. First, we run the specifications reported in Table 4 under various assumptions of curvature of the utilty function. Second, we have a subsample of our children for whom we have an experimental measure of risk preferences. We combine data from these two samples to assess the robustness of our results to accounting for risk attitudes.

\footnotetext{
${ }^{27}$ Table A2 shows similar results from the same specifications with a linear probability model.
} 


\subsubsection{Curvature of the utility function}

If risk aversion is not taken into account when measuring the discount rate, what might appear as impatience is really an unaccounted for aversion to risk (Andersen et al., 2008), and the effect of the discount rate would then be overestimated. Controlling for curvature of the utility function should lower the estimated discount rate. In turn, given this lower discount rate, the magnitude of the effect of the discount rate on graduating from high school should increase if the discount rate continues to have a similar effect on graduation outcomes once utility curvature is accounted for. The children in our study only made decisions over delayed consumption, however, as a calibration exercise, we can adjust the discount rate for different levels of risk aversion for a specific utility function to see how this affects the probability of finishing high school. To do this, we re-estimate the specifications from Table 4 under the assumption that all children share the same utility function.

\section{High school graduation results controlling for curvature of the utility function} Table 5 reports the results of this approach. These are estimates of the probability of graduating from high school on the discount rate, academic achievement, disciplinary referrals and other covariates under the assumption of a constant relative risk aversion (CRRA) utility function. There are five panels that show the coefficient estimates on the four different discount rate measures as the coefficient of relative risk aversion increases from $\sigma=0.45$ to 0.85 . We include $\sigma=0.65$ as this is the estimated coefficient of risk aversion from the Andersen, Harrison, Lau, and Rutstrom (2014) paper and serves as a good benchmark.

The results confirm that children with a higher discount rate are significantly less likely to finish high school, even assuming curvature of the utility function. We note that as the coefficient of risk aversion increases, the magnitude of the effect of the discount rate also increases and remains significant. This suggests a continued independent effect of impatience on high school graduation even for risk-averse children. Under the assumption of a homogeneous utility function, introducing risk aversion is similar to a rescaling of the discount rate. Table 5 shows the implicit standard deviation and range of the corrected discount factors. The implied marginal effects are comparable to those reported in Table 4.

This exercise shows that for risk aversion to explain our results, it would have to be the case that risk preferences and time preferences are correlated. For instance, this is possible if impatience and risk aversion are positively correlated and risk aversion discourages investment in human capital. The next section provides estimates that allow for a correlation between risk attitudes and discount rates and shows that children with higher discount rates are less likely to finish high school. These results can be explained by the fact that in our sample risk aversion is positively correlated with human capital accumulation. ${ }^{28}$ As discussed in the theory section, such outcomes are possible if risk aversion makes the short

\footnotetext{
${ }^{28}$ Evidence of heterogeneity of preferences and a positive correlation between risk aversion and impatience is provided by Alan, Browing, and Erjneas (forthcoming).
} 
term benefits of misbehavior less appealing. ${ }^{29}$

\subsubsection{Experimental measure of risk preferences}

Another approach to address the relevance of risk attitudes on the measurement and impact of discount rates is to collect additional experimental data as in Andersen, Harrison, Lau, and Rutstrom (2008) or to use alternative elicitation mechanisms as in Andreoni and Sprenger (2012). We did not collect such experimental data for the children in our sample. However, in a subsequent data collection effort in the last year we collected time preference data, we did measure risk attitudes for a large sample of children in the same school district $(\mathrm{n}=580)$. Some of the children for whom we have discount rate measures were also included in the risk attitudes study. That is, we have experimental choice data on time preferences and on risk attitudes for a subsample of our discount rate data $(n=211) .{ }^{30}$ We leverage this subsample and the larger risk attitudes sample to assess the importance of both time and risk preferences on high school graduation.

Risk experiment and estimation approach In the risk experiment, participants were presented with two lotteries and were asked to choose one. One lottery in the pair is safer $(S)$ and the other is riskier $(R)$. The safer lottery has a lower variance in payoff. Participants made five decisions over different pairs of lotteries, and the pairs are listed in Table 6 . The first decision is between the safer lottery $(S)$ of $\$ 30$ for sure and the riskier lottery $(R)$ of $\$ 40$ with a $20 \%$ chance, $\$ 30$ with a $75 \%$ chance and $\$ 0$ with a $5 \%$ chance. The second decision is between a safer lottery of $\$ 30$ with $25 \%$ chance and $\$ 0$ with $75 \%$ chance or a riskier lottery of $\$ 40$ with $20 \%$ chance and $\$ 0$ with $80 \%$ chance.

Each decision was shown on a separate page, and the lotteries were presented as the payoff the participant would get if one ball drawn from a bingo cage with 20 numbered balls had a particular number. For example, a $25 \%$ chance for a payoff of $\$ 30$ was shown as the payoff the child would get if the ball that came out of the bingo cage had the number $1,2,3,4$, or 5 . The instructions included steps to ensure the participants understood how the bingo cage worked, how the balls were linked to payoffs and the decision between the two lotteries. General experimental and payment procedures were similar to those used for the time preference experiment. One lottery was chosen at random for payment, and three children in each session were chosen to be paid. Payments were made with Walmart gift cards, and the children received payment within two days following the experiment. ${ }^{31}$

\footnotetext{
${ }^{29}$ Using a large sample from recently collected data, Castillo, Jordan, and Petrie (forthcoming) provide evidence that risk aversion is correlated with fewer disciplinary referrals.

${ }^{30}$ The small overlap in data collection efforts is because, at the time we collected the data on time preferences (in 2006-2008), the issue of a potential confound between time and risk preferences was not prevelant in the literature (e.g. the Andersen, Harrison, Lau, and Rutstrom (2008) paper examining time preferences controlling for risk preferences was published at the tail end of our data collection). In 2006, when we started collecting data, we did not think to collect both time and risk preference measures from the same child. The risk data used in this paper were collected in October 2008.

${ }^{31} \mathrm{~A}$ detailed description of the experimental data collection procedures is provided in Castillo, Jordan,
} 
For this set of lotteries, expected utility theory predicts that a decision maker should choose all $\mathrm{S}$ or all $\mathrm{R}$. The proportion of $\mathrm{S}$ choices can provide a measure of risk attitudes. For the estimation, we use dummy variables $d_{n}$ which equal 1 if the child chose $n$ safe decisions and 0 otherwise. This provides some flexibility in finding effects of risk attitudes on high school graduation. Some children have both time and risk decisions, and some have only one of them. In estimations, we will assign a value of zero to missing decisions and add dummy variables to account for the fact that some of the data is missing.

High school graduation results accounting for risk preferences Table 7 presents regression results accounting for risk attitudes. Column 1 presents the estimates on the subsample of children for whom we only have risk attitudes measures. We observe that children choosing safe in more decisions are more likely to graduate from high school. Columns 2-5 presents the results for the sample of children participating in either the risk or time preference experiments. The effect of the discount rate on graduating high school is similar to the estimates in Table 4, and the estimated parameters for risk attitudes do not change much. This suggests that the association between the discount rate and high school graduation is not due to risk preferences. Importantly, we note that risk aversion is positively, rather than negatively, correlated with high school graduation. This is contrary to what we would expect if risk aversion blunts the long-term returns from education. Our results are consistent with the theory that risk aversion could have a short-term effect by preventing some children from getting into trouble. Evidence that risk aversion predicts fewer disciplinary referrals up to two years after the experiment is provided in Castillo et al. (2011).

In sum, the results from this section confirm that the relevance of discount rates on human capital accumulation in children is strong and robust to accounting for risk attitudes.

\subsection{Robustness checks and potential mechanisms}

We present several robustness checks on our main results.

First, we examine how changes in the treatment of consistent choices affect the main results reported in Table 4. Table A3 reproduces the results in Table 4 without excluding the five percent of children with the highest distance to rational preferences. These data are comprised mainly of children who switched back and forth across each row of the time preference experiment. The results are similar to those in Table 4 and are consistent with attenuation due to measurement error. Table A4 reports results for the subsample of children who made consistent choices in the time preference experiment (roughly two-thirds of the original sample). We find similar and larger results to those in Table 4. This suggests again that measurement error is important and might lead to an underestimation of the

and Petrie (forthcoming). Data used in Castillo et al. (forthcoming) is from 2008 and 2011-2012. The risk preference instruments used in 2008 and 2011-2012 differ. 
effect of discount rates on graduation. Column 3 of Table A4 reports estimates excluding those children who always chose patiently or impatiently. These results are in the same direction but smaller and less precisely estimated.

Second, we examine how changes in the treatment of missing graduation status data affects the main results reported in Table 4. Building on Eckstein and Wolpin (1999)'s approach to studying the dynamics of educational attainment through credits earned in each year of high school, we construct an outcome variable that equals one if the child finished or was on track to finish high school in four years at the date of the last administrative record for the child. It is coded as zero otherwise. We use data on the cumulative number of credits earned to determine whether the child is on track because this shows progress towards an on-time graduation and these data are available for all children even if graduation status is not. ${ }^{32}$ Perhaps not surprisingly, the estimates using imputed data are in the same direction as those in Table 4 but smaller and less precisely estimated.

Third, we explore how sensitive our main results are to the assignment of a discount rate number based on choices, rather than a range. Our experimental design, even under the assumption of risk neutrality and monotonicity, can only identify a range for the discount rate, and our main results use the mid-point of the range. This procedure, replacing interval covariates with mid-points, can lead to inconsistent estimates (Hsiao, 1983; Manski and Tamer, 2002). Table A6 presents estimates where a dummy variable for each one of the possible ranges of the discount rates are included. ${ }^{33}$ The table presents the F-test associated with the hypothesis that these dummy variables are jointly significant. In all specifications, the dummies are jointly significant. This check shows that our estimates in Table 4 are robust to appropriate treatment of interval data.

Fourth, we provide evidence that the results are robust to alternative estimation strategies. Table A8 in the Appendix shows estimates that do not correct for attrition. The estimation is performed in the sub-sample of children with complete data. Graduation is over-represented in this sample. Table A8 shows that ignoring attrition produces smaller and less precisely estimated coefficients. This is consistent with the hypothesis that children struggling with school are more likely to relocate and be difficult to find. Table A9 in the Appendix presents estimates using multiple imputation methods to complete missing experimental data on risk preferences. The estimates also replace measures of household characteristics not available through school records (parents education and household structure) with proxy variables constructed from block-level census data. The estimates are very similar to those presented in the paper. If anything, the estimates suggests that using multi-

\footnotetext{
${ }^{32}$ Our on-track proxy and the actual graduation status of the subsample of children for whom we have graduation outcoes are highly correlated. The correlations are 0.746 ( $\mathrm{p}$-value $<0.0001$ ) using 9th grade data, 0.806 ( $\mathrm{p}$-value $<0.0001$ ) using 10 th grade data and 0.800 (p-value $<0.0001$ ) using 11 th grade data. With this measure, $72.2 \%$ of children are classified as being on track to graduate on time. This is comparable with the state level graduation rate of $71 \%$.

${ }^{33}$ To be able to implement this approach, we use the discount rate correcting for inconsistent choices whenever it applies.
} 
ple imputation might under-estimate the effect of risk preferences on high school completion. This provides evidence that our estimation strategy is appropriate.

Fifth, we provide direct evidence that discount rates are not strongly correlated with potential determinants of high school graduation by using the subsample household survey data. Table 8 shows the correlation between survey questions answered by parents, the child's graduation outcome and discount rate. Children whose parents have expectations they will go to college are more likely to graduate from high school, and children who have a sibling that dropped out of high school are less likely to graduate. Change of residence, usage of check-cashing services, history of eviction and incarceration are all negatively correlated with graduation. This is consistent with the household environment and financial constraints being important determinants of high school graduation. Importantly for our study, while these variables are correlated with high school graduation, they are not with a child's discount rate. The sample size of our household survey is too small to serve as an appropriate control in our regression analysis, however, these data provide supportive evidence against the hypothesis that an experimentally-measured discount rate captures the child's current circumstances rather than his preferences.

Finally, we explore to what extent disciplinary referrals in the 7th grade capture behavioral problems. The analyses thus far show that the effect of the discount rate on graduation is robust to the inclusion of disciplinary referrals, but it is unclear to what extent these referrals are manifestation of behavioral problems separate from intertemporal discounting. Table 9 reports the correlation between disciplinary referrals and survey questions answered by a subsample of 103 children. We find that children with more disciplinary referrals report that they pay less attention in class, do not enjoy school, get bored, give up on difficult tasks and do not concentrate. They also report to be less likely to follow rules and more likely to get in trouble and feel frustrated. The fact that children with more disciplinary referrals are more likely to report that they get in trouble speaks to the validity of the survey. Importantly for us, that disciplinary referrals are correlated with a tendency to give up and feel bored lends support to the claim that disciplinary referrals are a good proxy for impulsivity and present-biasedness. Our main results then suggest that discount rates can predict high school graduation for reasons other than impulsivity.

In sum, these robustness checks confirm our main results from Table 4 that more impatient children (those with a higher discount rate) are less likely to graduate from high school on time.

\subsection{Magnitude of effects on high school graduation}

To put our results in perspective, we examine the marginal effects of changes in the discount rate on graduation from high school evaluated at different levels of impatience and academic achievement. Table 10 reports these results for the example case of a 13-year old Black boy receiving free \& reduced price meals with no disciplinary referrals in the 7 th grade. 
Table 10 uses the coefficient estimates from Table 4 for the average switch measure of the discount rate (Column 1). Results are similar using the other measures of the discount rate. The results show that if a child becomes more impatient, and the discount rate increases from 0.2 to 1.2 (that is, it changes from the 15th percentile to the $73 \mathrm{rd}$ percentile), the probability of graduating from high school on time decreases but at a decreasing rate as the academic achievement of the child goes up. For a child in the lower decile of the academic achievement distribution, the probability of graduating from high school decreases significantly by 9.4 percentage points if the child's discount rate increases by $100 \%$. For a child in the upper decile of the academic achievement distribution, this decrease is 4.3 percentage points and is insignificant. At baseline, children in the lower decile of the academic achievement distribution have an estimated 50 percent chance of finishing high school on time while children in the upper decile have a 90 percent chance. This means that a child who is not doing well at school could increase the chance of graduating from high school by $18.8 \%$ by becoming more patient. The bottom portion of the Table 10 shows that while the effect of the discount rate on graduating interacts with the child's underlying level of academic achievement, a change in achievement from the lowest decile to the highest decile has a level effect regardless of the discount rate.

As a comparison, Murnane (2013) provides a review of dropout rates in the US. He documents a graduation gap of 8 percentage points between Black and White students, 4 percentage points between girls and boys and a large impact (30 percentage points) of socio-economic status. The results from Jordan, Kostandini, and Mykerezi (2012), using data from two nationally representative panel household surveys (NLSY 79 and 97), show that the graduation gap in percentage points between a white female and a white male is 4.6, a Hispanic female is 7.0, and a black female is 9.8. The results from these studies not only align well with our findings but also highlight the large magnitude of the effect of economic preferences on high school graduation.

\subsection{Mediation Analysis}

In this section, we discuss the interaction between discount rates and behavior prior to high school completion. Throughout the paper, we have used disciplinary referrals in the 7th grade as an additional control variable due to the fact that they are contemporary to the measurement of discount rates and might capture some of the non-pecuniary costs faced by children. The estimates show that disciplinary referrals in 7 th grade and time preferences are weakly correlated (Table A10 in the Appendix). Using an indicator variable for disciplinary referrals that equals 1 if a child had at least one disciplinary referral in the 7 th grade and 0 otherwise, we find that discount rates and disciplinary referrals in the 7 th grade are not related. Thus, the effect of discount rates is not likely to be mediated by behavior contemporaneous to preference elicitation.

We next explore how the effect of discount rates and behavior in the 7th grade are 
mediated by behavior in high school (disciplinary referrals in the 9th grade). First, we look at the effect of discount rates on graduation controlling for an indicator of disciplinary referrals in the 7th grade. Next, the effect of discount rates and behavior in the 7 th grade are estimated on the probability of having a disciplinary referral in the 9 th grade. ${ }^{34}$ Children with larger discount rates and bad behavior in the 7th grade are more likely to have a disciplinary referral in the 9 th grade. This confirms that disciplinary referrals in 7 th grade and preferences measured at the beginning of 8th grade are capturing different aspects of behavior.

Finally, we examine the net effect of discount rates and disciplinary referrals in the 7th grade on graduation controlling for having disciplinary referrals in the 9 th grade. ${ }^{35}$ Not surprisingly, we observe that the direct effect of both variables is reduced once intermediate outcomes are included in the regression. Table 11 summarizes these results by presenting the proportion of the effect of discount rates and disciplinary referrals in the 7 th grade captured by disciplinary referrals in the 9th grade. We find that about $35 \%$ of the effect of discount rates and $40 \%$ of the effect of disciplinary referrals in the 7 th grade manifest as behavioral problems in the 9 th grade. The fact that both past disciplinary problems and discount rates affect behavior in high school provides further evidence that preferences and non-pecuniary cost to human capital accumulation are important.

\section{Conclusions}

We set out to investigate if the individual discount rate of a child predicts on-time high school graduation. To do this, we collected an experimental measure of the discount rate of children at the beginning of 8th grade and tested if it predicted grduating from high school five years later. We find that a more impatient child (one with a higher discount rate) is significantly less likely to graduate from high school, even controlling for academic achievement, past disciplinary referrals, risk attitudes, demographics, household environment and parents' characteristics. A one standard deviation increase in the discount rate increases the probability of dropping out of high school by about four percentage points. Given that roughly one in five students drop out nationwide, this effect is substantial.

Our study shows that a child's discount rate is related to high school outcomes and this is not because the measure captures omitted household environmental variables or impulsivity. The evidence we present points to an independent effect of how a child values differences in future consumption. In addition, our results show that this effect is heterogeneous by level of academic achievement. The discount rate is a significant and large predictor of the probability of graduating from high school for those with relatively low academic achievement in 7th and 8th grades (as proxied by standardized test scores in math, reading, social studies

\footnotetext{
${ }^{34}$ These results are reported in Tables A11 and A12. We use indicator variables instead of number of disciplinary referrals as in Table 4 to facilitate interpretation of results.

${ }^{35}$ Table A13 in the Appendix.
} 
and science). Children who perform well in middle school are largely unaffected by their impatience, and this is mainly due to the fact that they are more likely to graduate from high school anyway. That is, impatience matters for those children who are relatively more at risk of not graduating. This suggests that programs aimed at low-performing students may need to take into account impatience in their design to have a measurable effect.

The findings from this study are a direct test of the hypothesis that unobservable differences in preferences and abilities are important determinants of labor market outcomes. Previous evidence on the importance of preferences has been mainly indirect. For instance, structural estimations of the decision to drop out of high school point to the importance of unaccounted for preferences, beliefs, non-pecuniary costs of schooling and productivity. Our results show that measured economic preferences can predict important educational decisions even five years in the future. Given that experimental measures are likely to suffer from significant measurement error, our results are encouraging. Theory and experiments can be combined to derive precise testable hypotheses, and collecting theoretically motivated measures of economic preferences can be used to determine policy implications. Policies that take into consideration heterogeneity of preferences and achievement and that aim to modify preferences could be fruitful. 


\section{References}

S. Alan, M. Browing, and M. Erjneas. Income and Consumption: a Micro Semistructural Analysis with Pervasive Heterogeneity. Journal of Political Economy, forthcoming.

Sule Alan and Seda Ertac. Fostering Patience in the Classroom: Results from Randomized Educational Intervention. Journal of Political Economy, forthcoming.

Sule Alan, Teodora Boneva, and Seda Ertac. Ever Failed, Try Again, Succeed Better: Results from a Randomized Educational Intervention on Grit. Working Paper, May 2015 .

K. L. Alexander, D. R. Entwisle, and C. S. Horsey. From First Grade Forward: Early Foundations of High School Dropout. Sociology of Education, 70(2):87-107, Apr 1997.

Mathilde Almlund, Angela Lee Duckworth, James Heckman, and Tim Kautz. Personality Psychology and Economics. In Hanushek, E. A. and Machin, S. and Woessmann, L., editor, Handbook of the Economics of Education, volume 4 of Handbooks in Economics, pages 1-181. 2011.

Steffen Andersen, Glenn W. Harrison, Morten I. Lau, and E. Elisabet Rutstrom. Eliciting Risk and Time Preferences. Econometrica, 76(3):583-618, May 2008.

Steffen Andersen, Glenn W. Harrison, Morten I. Lau, and E. Elisabet Rutstrom. Discounting Behavior: A Reconsideration. European Economic Review, 71:15-33, Oct 2014.

James Andreoni and Charles Sprenger. Estimating Time Preferences from Convex Budgets. American Economic Review, 102(7):3333-3356, Dec 2012.

R.B. Barsky, F.T. Juster, M.S. Kimball, and M.D. Shapiro. Preference Parameters and Behavioral Heterogeneity: An Experimental Approach in the Health and Retirement Study. Quarterly Journal of Economics, 112(2):537-579, May 1997.

Eric Bettinger and Robert Slonim. Patience Among Children. Journal of Public Economics, 91(1-2):343-363, February 2007.

Holger Bonin, Thomas Dohmen, Armin Falk, David Huffman, and Uwe Sunde. Crosssectional Earnings Risk and Occupational Sorting: The Role of Risk Attitudes. Labour Economics, 14(6):926-937, Dec 2007.

Stephen V. Burks, Jeffrey P. Carpenter, Lorenz Goette, and Aldo Rustichini. Cognitive Skills Affect Economic Preferences, Strategic Behavior, and Job Attachment. Proceedings of the National Academy of Sciences of the United States of America, 106(19):7745-7750, May 122009. 
Brian C. Cadena and Benjamin J. Keys. Human Capital and the Lifetime Costs of Impatience. American Economic Journal-Economic Policy, 7(3):126-153, Aug 2015.

Marco Castillo, Paul J. Ferraro, Jeffrey L. Jordan, and Ragan Petrie. The Today and Tomorrow of Kids: Time Preferences and Educational Outcomes of Children. Journal of Public Economics, 95(11-12):1377-1385, December 2011.

Marco Castillo, Jeffrey L. Jordan, and Ragan Petrie. Children's rationality, risk attitudes and field behavior. European Economic Review, forthcoming.

Christopher F. Chabris, David Laibson, Carrie L. Morris, Jonathon P. Schuldt, and Dmitry Taubinsky. Individual Laboratory-measured Discount Rates Predict Field Behavior. Journal of Risk and Uncertainty, 37(2-3):237-269, Dec 2008.

Robin P. Cubitt and Daniel Read. Can Intertemporal Choice Experiments Elicit Time Preferences for Consumption? Experimental Economics, 10(4):369-389, Dec 2007.

S DellaVigna and MD Paserman. Job search and impatience. Journal of Labor Economics, 23(3):527-588, Jul 2005.

Z. Eckstein and K. I. Wolpin. Why Youths Drop Out of High School: The Impact of Preferences, Opportunities, and Abilities. Econometrica, 67(6):1295-1339, Nov 1999.

Richard B. Freeman. The Economics of Crime. Handbooks in Economics, vol. 5. Amsterdam; New York and Oxford: Elsevier Science, North-Holland, 1999.

Paul Gertler, James Heckman, Rodrigo Pinto, Arianna Zanolini, Christel Vermeersch, Susan Walker, Susan M. Chang, and Sally Grantham-Zmcgregor. Labor Market Returns to Early Childhood Stimulation: A 20-year Followup to an Experimental Intervention in Jamaica. National Bureau of Economic Research w19185, 2013.

Bart H. H. Golsteyn, Hans Gronqvist, and Lena Lindahl. Adolescent Time Preferences Predict Lifetime Outcomes. Economic Journal, 124(580, F):F739-F761, Nov 2014.

Yoram Halevy. Strotz meets Allais: Diminishing Impatience and the Certainty Effect. American Economic Review, 98(3):1145-1162, Jun 2008.

Yoram Halevy. Some Comments on the Use of Monetary and Primary Rewards in the Measurement of Time Preferences. Working Paper, 2014.

G. W. Harrison, M. I. Lau, and M. B. Williams. Estimating Individual Discount Rates in Denmark: A Field Experiment. American Economic Review, 92(5):1606-1617, Dec 2002.

J. Heckman and Y. Rubinstein. The importance of noncognitive skills: Lessons from the GED testing program. American Economic Review, 91(2):145-149, MAY 2001. 
James Heckman, Rodrigo Pinto, and Peter Savelyev. Understanding the Mechanisms Through Which an Influential Early Childhood Program Boosted Adult Outcomes. American Economic Review, 103(6):2052-2086, Oct 2013.

James J. Heckman and Paul A. LaFontaine. The American High School Graduation Rate: Trends and Levels. Review of Economic and Statistics, 92(2):244-262, May 2010.

James J. Heckman, Lance J. Lochner, and Petra E. Todd. Fifty Years of Mincer Earnings Regressions. National Bureau of Economic Research w14415, 2003.

James J. Heckman, Jora Stixrud, and Sergio Urzua. The Effects of Cognitive and Noncognitive Abilities on Labor Market Outcomes and Social Behavior. Journal of Labor Economics, 24(3):411-482, July 2006.

John L. Horn. A Rationale and Test for the Number of Factors in Factor Analysis. Psychometrika, 30(2):179-185, 1965.

C. Hsiao. Regression Analysis with a Categorized Explanatory Variable. In S. Karlin, T. Amemiya, and L. Goodman, editors, Studies in Econometrics, Time Series, and Multivariate Statistics, pages 93 - 129. Academic Press, 1983.

David S. Johnson, Jonathan A. Parker, and Nicholas S. Souleles. Household expenditure and the income tax rebates of 2001. American Economic Review, 96(5):1589-1610, Dec 2006 .

J. L. Jordan, G. Kostandini, and E. Mykerezi. Rural and urban high school dropout rates: Are they different? Journal of Research in Rural Education, 27(12):1-21, 2012.

Miles S. Kimball, Claudia R. Sahm, and Matthew D. Shapiro. Imputing Risk Tolerance From Survey Responses. Journal of the American Statistical Association, 103(483):10281038, Sep 2008.

K. Lang and P. A. Ruud. Returns to Schooling, Implicit Discount Rates and Black-White Wage Differentials. Review of Economic and Statistics, 68(1):41-47, Feb 1986.

C. Manski and E. Tamer. Inference on Regressions with Interval Data on a Regressor or Outcome. Econometrica, 70(2):519-546, Mar 2002.

Stephan Meier and Charles Sprenger. Present-Biased Preferences and Credit Card Borrowing. American Economic Journal - Applied Economics, 2(1):193-210, Jan 2010.

W. Mischel, Y. Shoda, and P.K. Peake. The Nature of Adolescent Competencies Predicted by Preschool Delay of Gratification. Journal of Personality and Social Psychology, 54(4): 687-696, Apr 1988. 
W. Mischel, Y. Shoda, and M. L. Rodriguez. Delay of Gratification in Children. Science, 244(4907):933-938, May 261989.

Terrie E. Moffitt, Louise Arseneault, Daniel Belsky, Nigel Dickson, Robert J. Hancox, HonaLee Harrington, Renate Houts, Richie Poulton, Brent W. Roberts, Stephen Ross, Malcolm R. Sears, W. Murray Thomson, and Avshalom Caspi. A Gradient of Childhood Self-control Predicts Health, Wealth, and Public Safety. Proceedings of the American Academy of Sciences, 108(7):2693-2698, Feb 152011.

Richard J. Murnane. US High School Graduation Rates: Patterns and Explanations. Journal of Economic Literature, 51(2):370-422, Jun 2013.

Philip Oreopoulos. Estimating Average and Local Average Treatment Effects of Education when Compulsory Schooling Laws Eeally Matter. American Economic Review, 96(1): 152-175, Mar 2006.

Philip Oreopoulos. Do Dropouts Drop Out Too Soon? Wealth, Health and Happiness from Compulsory Schooling. Journal of Public Economics, 91(11-12):2213-2229, Dec 2007.

Jonathan A. Parker, Nicholas S. Souleles, David S. Johnson, and Robert McClelland. Consumer Spending and the Economic Stimulus Payments of 2008. American Economic Review, 103(6):2530-2553, Oct 2013.

R. W. Rumberger. Dropping Out of Middle School - A Multilevel Analysis of Students and Schools. American Educational Research Journal, 32(3):583-625, Fall 1995.

Kota Saito. Strotz Meets Allais: Diminishing Impatience and the Certainty Effect: Comment. American Economic Review, 101(5):2271-2275, Aug 2011.

Y. Shoda, W. Mischel, and P.K. Peake. Predicting Adolescent Cognitive and Self-regulatory Competences from Preschool Delay of Gratification - Identifying Diagnostic Conditions. Developmental Psychology, 26(6):978-986, Nov 1990.

Matthias Sutter, Martin G. Kocher, Daniela Glaetzle-Ruetzler, and Stefan T. Trautmann. Impatience and Uncertainty: Experimental Decisions Predict Adolescents' Field Behavior. American Economic Review, 103(1):510-531, 2013.

J. M. Wooldridge. Econometric Analysis of Cross Section and Panel Data, 2nd Edition. In Econometric Analysis of Cross Section and Panel Data, 2nd Edition, pages 1-1064. 2010. 


\section{Figures and Tables}
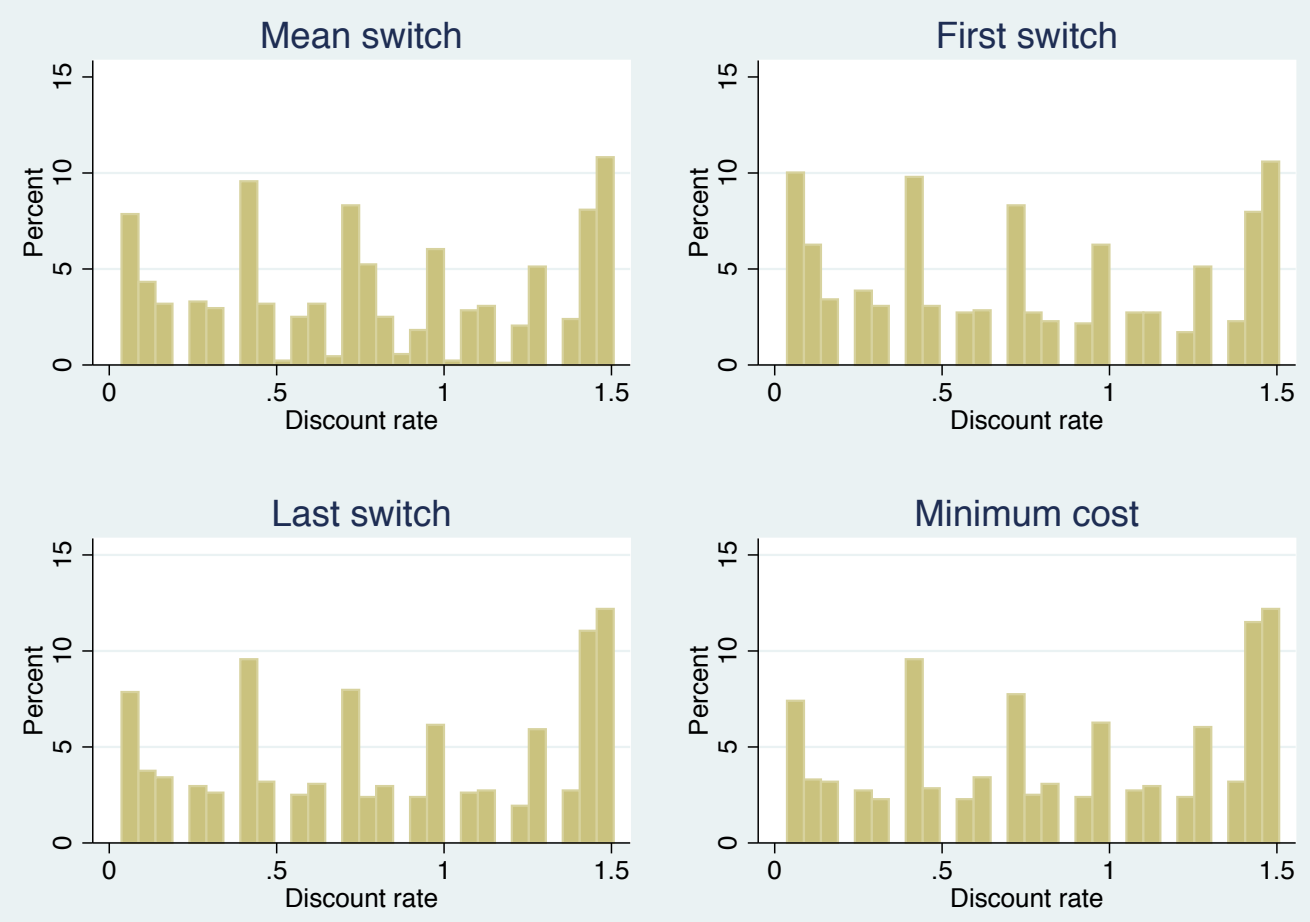

Figure 1: Distribution of discount rates by four measures (average switch, first switch, last switch and minimum cost to make consistent). 
Table 1. Descriptive Statistics

\begin{tabular}{lccc}
\hline Variable & mean & sd & $\mathrm{N}$ \\
\hline Age & 13.8 & 0.56 & 866 \\
Male & 48.4 & 50.0 & 847 \\
Black & 46.6 & 49.9 & 847 \\
Hispanic \& Multiracial & 4.3 & 20.2 & 847 \\
Free \& reduced price meal & 63.5 & 48.2 & 846 \\
Math score (7th grade) & 0.56 & 0.09 & 791 \\
Reading score (7th grade) & 0.56 & 0.07 & 792 \\
Science score (7th grade) & 0.53 & 0.12 & 787 \\
Social studies score (7th grade) & 0.52 & 0.12 & 786 \\
Special education & 24.8 & 43.2 & 878 \\
Gifted & 8.8 & 28.3 & 878 \\
Disciplinary referrals (7th grade) & 1.9 & 3.0 & 814 \\
Graduation rate (for observed graduation status) & 0.81 & 0.40 & 621 \\
\hline \hline
\end{tabular}

Note: some individuals are missing demographic data (sex, race and age), disciplinary referrals and test scores (because they were not in the school system on testing dates). 
Table 2. Decisions faced by participants in the experiment

\begin{tabular}{|c|c|c|c|c|}
\hline Decision & $\begin{array}{l}\text { Paid one } \\
\text { month from now }\end{array}$ & or & $\begin{array}{c}\text { Paid Seven } \\
\text { months from now }\end{array}$ & $\begin{array}{l}\text { Implied annual } \\
\text { interest rate }^{\mathrm{a}}\end{array}$ \\
\hline 1 & $\$ 49$ & or & $\$ 50.83$ & 7.35 \\
\hline 2 & $\$ 49$ & or & $\$ 52.71$ & 14.70 \\
\hline 3 & $\$ 49$ & or & $\$ 54.66$ & 22.05 \\
\hline 4 & $\$ 49$ & or & $\$ 56.66$ & 29.40 \\
\hline 5 & $\$ 49$ & or & $\$ 58.72$ & 36.75 \\
\hline 6 & $\$ 49$ & or & $\$ 60.85$ & 44.10 \\
\hline 7 & $\$ 49$ & or & $\$ 63.04$ & 51.45 \\
\hline 8 & $\$ 49$ & or & $\$ 65.29$ & 58.80 \\
\hline 9 & $\$ 49$ & or & $\$ 67.61$ & 66.15 \\
\hline 10 & $\$ 49$ & or & $\$ 70.00$ & 73.50 \\
\hline 11 & $\$ 49$ & or & $\$ 72.46$ & 80.85 \\
\hline 12 & $\$ 49$ & or & $\$ 74.99$ & 88.20 \\
\hline 13 & $\$ 49$ & or & $\$ 77.59$ & 95.55 \\
\hline 14 & $\$ 49$ & or & $\$ 80.27$ & 102.90 \\
\hline 15 & $\$ 49$ & or & $\$ 83.03$ & 110.25 \\
\hline 16 & $\$ 49$ & or & $\$ 85.86$ & 117.60 \\
\hline 17 & $\$ 49$ & or & $\$ 88.78$ & 124.95 \\
\hline 18 & $\$ 49$ & or & $\$ 91.77$ & 132.30 \\
\hline 19 & $\$ 49$ & or & $\$ 94.85$ & 139.65 \\
\hline 20 & $\$ 49$ & or & $\$ 98.02$ & 147.00 \\
\hline
\end{tabular}

${ }^{\text {a }}$ Participants did not see this column on their decision sheets. The column is included to show the implied annual interest rate associated with each choice. 
Table 3. Differences between students with known and unknown graduation outcomes

\begin{tabular}{|c|c|c|c|c|c|}
\hline & \multicolumn{2}{|c|}{$\begin{array}{l}\text { Known gradu- } \\
\text { ation outcome }\end{array}$} & \multicolumn{3}{|c|}{$\begin{array}{l}\text { Unknown } \\
\text { graduation } \\
\text { outcome }\end{array}$} \\
\hline & value & $\mathrm{n}$ & value & $\mathrm{n}$ & $\begin{array}{l}\text { p-value } \\
(2 \text {-sided })\end{array}$ \\
\hline Disciplinary referrals (7th grade) & 1.463 & 771 & 2.617 & 350 & 0.000 \\
\hline Academic achievement & 0.142 & 793 & -0.230 & 365 & 0.000 \\
\hline Age & 13.720 & 807 & 13.959 & 378 & 0.000 \\
\hline Male & 0.489 & 789 & 0.501 & 365 & 0.702 \\
\hline Black & 0.468 & 789 & 0.381 & 365 & 0.006 \\
\hline Hispanic \& Multi-racial & 0.034 & 789 & 0.060 & 365 & 0.041 \\
\hline Free \& reduced price meal & 0.588 & 789 & 0.691 & 363 & 0.001 \\
\hline Special education & 0.224 & 807 & 0.407 & 378 & 0.000 \\
\hline Accumulated credits one year after experiment & 0.028 & 807 & 0.019 & 378 & 0.520 \\
\hline Accumulated credits two years after experiment & 5.591 & 807 & 3.474 & 378 & 0.000 \\
\hline Value of house (in log) & 10.240 & 807 & 9.986 & 378 & 0.283 \\
\hline Filed for homestead exemption & 0.524 & 807 & 0.407 & 378 & 0.000 \\
\hline Two-parent household & 0.660 & 350 & 0.624 & 173 & 0.422 \\
\hline Mother's highest education level - high school & 0.463 & 350 & 0.337 & 172 & 0.006 \\
\hline Father's highest education level - high school & 0.368 & 351 & 0.301 & 173 & 0.130 \\
\hline Mother's highest education level - college & 0.306 & 350 & 0.301 & 173 & 0.905 \\
\hline Father's highest education level - college & 0.222 & 351 & 0.249 & 173 & 0.502 \\
\hline Household survey response rate & 0.318 & 807 & 0.220 & 378 & 0.000 \\
\hline
\end{tabular}


Table 4. Probit regression of high school graduation in four years (marginal effects) (using observations with known graduation outcome and a cost to make consistent that is in the lower 95-percentile)

\begin{tabular}{|c|c|c|c|c|}
\hline VARIABLES & $\begin{array}{l}\text { Average switch } \\
\text { (1) }\end{array}$ & $\begin{array}{c}\text { First switch } \\
\text { (2) }\end{array}$ & $\begin{array}{c}\text { Last switch } \\
\text { (3) }\end{array}$ & $\begin{array}{l}\text { Min. Cost } \\
\text { (4) }\end{array}$ \\
\hline \multirow[t]{3}{*}{ Discount rate } & $-0.091^{* *}$ & $-0.087^{* *}$ & $-0.080^{*}$ & $-0.079^{*}$ \\
\hline & {$[0.043]$} & {$[0.042]$} & {$[0.043]$} & {$[0.044]$} \\
\hline & $(0.034)$ & $(0.037)$ & $(0.063)$ & $(0.071)$ \\
\hline \multirow[t]{3}{*}{ Disciplinary referrals (7th grade) } & $-0.023^{* * *}$ & $-0.023^{* * *}$ & $-0.023^{* * *}$ & $-0.023^{* * *}$ \\
\hline & {$[0.006]$} & {$[0.006]$} & {$[0.006]$} & {$[0.006]$} \\
\hline & $(0.000)$ & $(0.000)$ & $(0.000)$ & $(0.000)$ \\
\hline \multirow[t]{3}{*}{ Academic achievement } & $0.232^{* * *}$ & $0.233^{* * *}$ & $0.228^{* * *}$ & $0.229 * * *$ \\
\hline & {$[0.044]$} & {$[0.044]$} & {$[0.043]$} & {$[0.043]$} \\
\hline & $(0.000)$ & $(0.000)$ & $(0.000)$ & $(0.000)$ \\
\hline \multirow[t]{3}{*}{ Age } & $-0.147^{* * *}$ & $-0.147 * * *$ & $-0.140^{* * *}$ & $-0.141^{* * *}$ \\
\hline & {$[0.037]$} & {$[0.037]$} & {$[0.036]$} & {$[0.037]$} \\
\hline & $(0.000)$ & $(0.000)$ & $(0.000)$ & $(0.000)$ \\
\hline \multirow[t]{3}{*}{ Male } & $-0.082^{*}$ & $-0.085^{* *}$ & $-0.079 *$ & $-0.079^{*}$ \\
\hline & {$[0.042]$} & {$[0.042]$} & {$[0.042]$} & {$[0.042]$} \\
\hline & $(0.050)$ & $(0.045)$ & $(0.060)$ & $(0.061)$ \\
\hline \multirow[t]{3}{*}{ Black } & $0.185^{* * *}$ & $0.184^{* * *}$ & $0.188^{* * *}$ & $0.189^{* * *}$ \\
\hline & {$[0.044]$} & {$[0.044]$} & {$[0.043]$} & {$[0.043]$} \\
\hline & $(0.000)$ & $(0.000)$ & $(0.000)$ & $(0.000)$ \\
\hline \multirow[t]{3}{*}{ Hispanic \& Multi-racial } & 0.121 & 0.122 & 0.121 & 0.121 \\
\hline & {$[0.087]$} & {$[0.087]$} & {$[0.085]$} & {$[0.085]$} \\
\hline & $(0.164)$ & $(0.161)$ & $(0.155)$ & $(0.154)$ \\
\hline \multirow[t]{3}{*}{ Free \& reduced price meal } & $-0.164^{* * *}$ & $-0.162 * * *$ & $-0.167 * * *$ & $-0.168^{* * *}$ \\
\hline & {$[0.052]$} & {$[0.052]$} & {$[0.051]$} & {$[0.051]$} \\
\hline & $(0.002)$ & $(0.002)$ & $(0.001)$ & $(0.001)$ \\
\hline \multirow[t]{3}{*}{ Special education } & 0.052 & 0.053 & 0.043 & 0.044 \\
\hline & {$[0.048]$} & {$[0.048]$} & {$[0.048]$} & {$[0.048]$} \\
\hline & $(0.272)$ & $(0.270)$ & $(0.367)$ & $(0.362)$ \\
\hline Observations & 547 & 546 & 545 & 545 \\
\hline
\end{tabular}

Additional covariates included in regressions but not reported include: dummy for having chosen inconsistently, dummy for homestead exemption filing, house value (in log), dummy for two-parent household, dummy for mother's highest educ is high school, dummy for father's highest educ is high school, dummy for mother's highest educ is college, dummy for father's highest educ is college. Missing values replaced with the average at the census track level. Standard errors in brackets, and robust p-values in parentheses. ${ }^{* * *} \mathrm{p}<0.01,{ }^{* *} \mathrm{p}<0.05,{ }^{*} \mathrm{p}<0.10$ 
Table 5. Maximum-likelihood estimates of risk-aversion corrected discount rate on High School graduation (marginal effects)

\begin{tabular}{|c|c|c|c|c|}
\hline \multicolumn{5}{|c|}{ Utility function: $u(c)=\frac{(50+c)^{(1-\sigma)}}{1-\sigma}$} \\
\hline & $\begin{array}{l}\text { Average } \\
\text { switch }\end{array}$ & $\begin{array}{c}\text { First } \\
\text { switch }\end{array}$ & $\begin{array}{c}\text { Last } \\
\text { switch }\end{array}$ & $\begin{array}{l}\text { Minimum } \\
\text { cost }\end{array}$ \\
\hline \multicolumn{5}{|c|}{$\sigma=0.45$} \\
\hline \multirow[t]{3}{*}{ Discount rate } & $-0.294^{* *}$ & $-0.281 * *$ & $-0.261^{*}$ & $-0.257^{*}$ \\
\hline & {$[0.138]$} & {$[0.134]$} & {$[0.139]$} & [0.140] \\
\hline & $(0.033)$ & $(0.036)$ & $(0.060)$ & $(0.067)$ \\
\hline SD(D.R.) & 0.150 & 0.156 & 0.155 & 0.154 \\
\hline \multirow[t]{2}{*}{ Span(D.R.) } & 0.453 & 0.453 & 0.453 & 0.453 \\
\hline & \multicolumn{3}{|c|}{$\sigma=0.55$} & \\
\hline \multirow[t]{3}{*}{ Discount rate } & $-0.361^{* *}$ & $-0.345^{* *}$ & $-0.320^{*}$ & $-0.315^{*}$ \\
\hline & {$[0.169]$} & {$[0.165]$} & {$[0.170]$} & {$[0.172]$} \\
\hline & $(0.033)$ & $(0.036)$ & $(0.060)$ & $(0.067)$ \\
\hline SD(D.R.) & 0.122 & 0.127 & 0.127 & 0.125 \\
\hline \multirow[t]{2}{*}{ Span(D.R.) } & 0.369 & 0.369 & 0.369 & 0.369 \\
\hline & \multicolumn{3}{|c|}{$\sigma=0.65$} & \\
\hline \multirow[t]{3}{*}{ Discount rate } & $-0.466^{* *}$ & $-0.445^{* *}$ & $-0.413^{*}$ & $-0.406^{*}$ \\
\hline & {$[0.218]$} & {$[0.213]$} & {$[0.219]$} & {$[0.222]$} \\
\hline & $(0.033)$ & $(0.036)$ & $(0.060)$ & $(0.067)$ \\
\hline SD(D.R.) & 0.0949 & 0.0985 & 0.0981 & 0.0972 \\
\hline \multirow[t]{2}{*}{ Span(D.R.) } & 0.286 & 0.286 & 0.286 & 0.286 \\
\hline & \multicolumn{3}{|c|}{$\sigma=0.75$} & \\
\hline \multirow[t]{3}{*}{ Discount rate } & $-0.654^{* *}$ & $-0.626^{* *}$ & $-0.580^{*}$ & $-0.570^{*}$ \\
\hline & {$[0.307]$} & [0.299] & {$[0.308]$} & {$[0.312]$} \\
\hline & $(0.033)$ & $(0.036)$ & $(0.060)$ & $(0.067)$ \\
\hline SD(D.R.) & 0.068 & 0.070 & 0.070 & 0.069 \\
\hline \multirow[t]{2}{*}{ Span(D.R.) } & 0.204 & 0.204 & 0.204 & 0.204 \\
\hline & & $=0.85$ & & \\
\hline \multirow[t]{3}{*}{ Discount rate } & $-1.095^{* *}$ & $-1.047^{* *}$ & $-0.969^{*}$ & $-0.954^{*}$ \\
\hline & {$[0.513]$} & {$[0.500]$} & {$[0.516]$} & {$[0.522]$} \\
\hline & $(0.033)$ & $(0.036)$ & $(0.060)$ & $(0.068)$ \\
\hline SD(D.R.) & 0.040 & 0.042 & 0.042 & 0.041 \\
\hline Span(D.R.) & 0.122 & 0.122 & 0.122 & 0.122 \\
\hline Observations & 782 & 780 & 780 & 781 \\
\hline
\end{tabular}

Controls (not shown): Male, age, black, academic achievement, Hisp \& multiracial, special education, free \& reduced price meal, cohort year. Robust s.e. in brackets, p-values in parentheses. ${ }^{* * *} \mathrm{p}<0.01,{ }^{* *} \mathrm{p}<0.05,{ }^{*} \mathrm{p}<0.10$ 
Table 6. Lotteries used in the risk experiment

\begin{tabular}{cccc}
\hline Lottery Pair & Safer lottery & & Riskier lottery \\
\hline 1 & $(\$ 30,1)$ & or & $(\$ 40,0.2 ; \$ 30,0.75, \$ 0,0.05)$ \\
2 & $(\$ 30,0.25 ; \$ 0,0.75)$ & or & $(\$ 40,0.2 ; \$ 0,0.8)$ \\
3 & $(\$ 30,1)$ & or & $(\$ 40,0.8, \$ 0,0.2)$ \\
4 & $(\$ 40,0.2 ; \$ 30,0.75 ; \$ 0,0.05)$ & or & $(\$ 40,0.8 ; \$ 0,0.2)$ \\
5 & $(\$ 40,0.75 ; \$ 30,0.25)$ & or & $(\$ 40,0.95 ; \$ 0,0.05)$ \\
\hline
\end{tabular}

Each lottery lists the dollar payoff and the probability associated with that payoff. All probabilities in any lottery sum to one. 
Table 7. Probit regression of high school graduation in four years (marginal effects) known graduation outcome and controlling for risk aversion

\begin{tabular}{|c|c|c|c|c|c|}
\hline & $\begin{array}{l}\text { Only risk } \\
\text { (1) }\end{array}$ & $\begin{array}{c}\text { Average switch } \\
\text { (2) }\end{array}$ & $\begin{array}{c}\text { First switch } \\
\text { (3) }\end{array}$ & $\begin{array}{c}\text { Last switch } \\
\text { (4) }\end{array}$ & $\begin{array}{l}\text { Min. Cost } \\
\text { (5) }\end{array}$ \\
\hline \multirow[t]{3}{*}{ Discount rate } & & $-0.085^{* *}$ & $-0.085^{* *}$ & $-0.073^{*}$ & $-0.075^{*}$ \\
\hline & & {$[0.041]$} & {$[0.038]$} & {$[0.040]$} & {$[0.041]$} \\
\hline & & $(0.040)$ & $(0.027)$ & $(0.069)$ & $(0.065)$ \\
\hline \multirow[t]{3}{*}{ One safe decisions } & 0.071 & 0.117 & 0.116 & 0.119 & 0.119 \\
\hline & {$[0.046]$} & {$[0.079]$} & {$[0.079]$} & {$[0.079]$} & {$[0.079]$} \\
\hline & $(0.117)$ & $(0.137)$ & $(0.142)$ & $(0.130)$ & $(0.132)$ \\
\hline \multirow[t]{3}{*}{ Two safe decisions } & 0.019 & 0.042 & 0.041 & 0.042 & 0.042 \\
\hline & {$[0.069]$} & {$[0.107]$} & {$[0.107]$} & {$[0.107]$} & {$[0.107]$} \\
\hline & $(0.778)$ & $(0.696)$ & $(0.699)$ & $(0.698)$ & $(0.697)$ \\
\hline \multirow[t]{3}{*}{ Three safe decisions } & $0.118^{* *}$ & $0.139^{*}$ & $0.138^{*}$ & $0.140^{*}$ & $0.140^{*}$ \\
\hline & {$[0.053]$} & {$[0.075]$} & {$[0.076]$} & {$[0.076]$} & {$[0.076]$} \\
\hline & $(0.024)$ & $(0.065)$ & $(0.068)$ & $(0.065)$ & $(0.064)$ \\
\hline \multirow[t]{3}{*}{ Four safe decisions } & $0.103^{* *}$ & $0.144^{* *}$ & $0.144^{* *}$ & $0.144^{* *}$ & $0.144^{* *}$ \\
\hline & {$[0.052]$} & {$[0.071]$} & {$[0.071]$} & {$[0.071]$} & {$[0.071]$} \\
\hline & $(0.048)$ & $(0.041)$ & $(0.041)$ & $(0.043)$ & $(0.043)$ \\
\hline \multirow[t]{3}{*}{ Five safe decisions } & 0.054 & 0.089 & 0.089 & 0.089 & 0.089 \\
\hline & {$[0.055]$} & {$[0.092]$} & {$[0.091]$} & {$[0.092]$} & {$[0.092]$} \\
\hline & $(0.324)$ & $(0.331)$ & $(0.332)$ & $(0.336)$ & $(0.335)$ \\
\hline \multirow[t]{3}{*}{ Disciplinary referrals (7th grade) } & $-0.011^{* *}$ & $-0.024^{* * *}$ & $-0.024^{* * *}$ & $-0.024^{* * *}$ & $-0.024 * * *$ \\
\hline & {$[0.005]$} & {$[0.005]$} & {$[0.005]$} & {$[0.005]$} & {$[0.005]$} \\
\hline & $(0.020)$ & $(0.000)$ & $(0.000)$ & $(0.000)$ & $(0.000)$ \\
\hline \multirow[t]{3}{*}{ Academic achievement } & $0.169^{* * *}$ & $0.227^{* * *}$ & $0.227^{* * *}$ & $0.228^{* * *}$ & $0.228^{* * *}$ \\
\hline & {$[0.041]$} & {$[0.036]$} & {$[0.036]$} & {$[0.036]$} & {$[0.036]$} \\
\hline & $(0.000)$ & $(0.000)$ & $(0.000)$ & $(0.000)$ & $(0.000)$ \\
\hline \multirow[t]{3}{*}{ Age } & $-0.144^{* * *}$ & $-0.165^{* * *}$ & $-0.165^{* * *}$ & $-0.165^{* * *}$ & $-0.165^{* * *}$ \\
\hline & {$[0.029]$} & {$[0.029]$} & {$[0.030]$} & {$[0.030]$} & {$[0.030]$} \\
\hline & $(0.000)$ & $(0.000)$ & $(0.000)$ & $(0.000)$ & $(0.000)$ \\
\hline \multirow[t]{3}{*}{ Male } & -0.041 & -0.054 & $-0.054^{*}$ & $-0.054^{*}$ & $-0.054^{*}$ \\
\hline & {$[0.030]$} & {$[0.033]$} & {$[0.033]$} & {$[0.033]$} & {$[0.033]$} \\
\hline & $(0.179)$ & $(0.101)$ & $(0.097)$ & $(0.098)$ & $(0.098)$ \\
\hline \multirow[t]{3}{*}{ Black } & $0.183^{* * *}$ & $0.170^{* * *}$ & $0.169^{* * *}$ & $0.172^{* * *}$ & $0.173^{* * *}$ \\
\hline & {$[0.041]$} & {$[0.036]$} & {$[0.036]$} & {$[0.036]$} & {$[0.036]$} \\
\hline & $(0.000)$ & $(0.000)$ & $(0.000)$ & $(0.000)$ & $(0.000)$ \\
\hline \multirow[t]{3}{*}{ Hispanic \& Multi-racial } & $0.064^{*}$ & $0.113^{*}$ & $0.113^{*}$ & $0.113^{*}$ & $0.113^{*}$ \\
\hline & {$[0.034]$} & {$[0.066]$} & {$[0.065]$} & {$[0.066]$} & {$[0.066]$} \\
\hline & $(0.063)$ & $(0.087)$ & $(0.084)$ & $(0.086)$ & $(0.088)$ \\
\hline \multirow[t]{3}{*}{ Free \& reduced price meal } & $-0.109 * * *$ & $-0.136^{* * *}$ & $-0.135^{* * *}$ & $-0.136^{* * *}$ & $-0.135^{* * *}$ \\
\hline & {$[0.038]$} & {$[0.041]$} & {$[0.041]$} & {$[0.041]$} & {$[0.041]$} \\
\hline & $(0.004)$ & $(0.001)$ & $(0.001)$ & $(0.001)$ & $(0.001)$ \\
\hline \multirow[t]{3}{*}{ Special education } & 0.027 & $0.067^{*}$ & $0.068^{*}$ & $0.068^{*}$ & $0.068^{*}$ \\
\hline & {$[0.028]$} & {$[0.036]$} & {$[0.036]$} & {$[0.036]$} & {$[0.036]$} \\
\hline & $(0.340)$ & $(0.060)$ & $(0.057)$ & $(0.058)$ & $(0.057)$ \\
\hline Observations & 350 & 762 & 762 & 762 & 762 \\
\hline
\end{tabular}

Additional covariates included in regressions but not reported include: dummy for having chosen inconsistently, dummy for homestead exemption filing, house value (in log), dummy for two-parent household, dummy for mother's highest educ is high school, dummy for father's highest educ is high school, dummy for mother's highest educ is college, dummy for father's highest educ is college. Missing values replaced with the average at the census track level. Standard errors in brackets, and robust $\mathrm{p}$-values in parentheses. ${ }^{* * *} \mathrm{p}<0.01,{ }^{* *} \mathrm{p}<0.05,{ }^{*} \mathrm{p}<0.10$. 
Table 8. Correlations between the parents' answers to household survey, the child's graduation status and the child's discount rate

\begin{tabular}{|c|c|c|c|c|}
\hline \multirow[b]{2}{*}{ Household survey question } & \multicolumn{2}{|c|}{$\begin{array}{l}\text { Child graduated? } \\
\qquad(\mathrm{N}=207)\end{array}$} & \multicolumn{2}{|c|}{$\begin{array}{l}\text { Child's discount rate } \\
\qquad(\mathrm{N}=158)\end{array}$} \\
\hline & $\rho$ & p-value & $\rho$ & p-value \\
\hline 1. Do you think your child will go to college? & $0.155^{* *}$ & 0.026 & 0.004 & 0.957 \\
\hline $\begin{array}{l}\text { 2. Does your child have any siblings (including step-siblings) who } \\
\text { have dropped out of school? }\end{array}$ & $-0.155^{* *}$ & 0.026 & 0.056 & 0.484 \\
\hline $\begin{array}{l}\text { 3. Do you regularly attend Parent-Teacher Organization (PTO) } \\
\text { meetings at your childs school? }\end{array}$ & -0.040 & 0.571 & 0.064 & 0.421 \\
\hline 4. Are you, or your partner, currently employed? & -0.008 & 0.819 & -0.052 & 0.122 \\
\hline $\begin{array}{l}\text { 5. How many times has your child moved residences in the past five } \\
\text { years? }\end{array}$ & $-0.194^{* * *}$ & 0.005 & -0.052 & 0.518 \\
\hline 6. Have you ever used the services of a check-cashing service? & $-0.144^{* *}$ & 0.039 & $0.134^{*}$ & 0.093 \\
\hline 7. Have you ever taken out a loan? & 0.089 & 0.202 & -0.093 & 0.247 \\
\hline 8. Have you taken a loan from a friend or family member? & $-0.158^{* *}$ & 0.041 & 0.087 & 0.337 \\
\hline 9. Have you taken a loan from a government loan program? & 0.008 & 0.917 & -0.007 & 0.935 \\
\hline 10. Have you taken a loan from a bank? & $0.262^{* * *}$ & 0.001 & -0.042 & 0.645 \\
\hline 11. Have you taken a loan from a car title company? & -0.092 & 0.233 & 0.004 & 0.962 \\
\hline 12. Have you taken a loan from a pawn shop? & 0.006 & 0.935 & -0.025 & 0.786 \\
\hline 13. Have you taken a loan from a pay-day loan service? & 0.117 & 0.130 & $-0.150^{*}$ & 0.094 \\
\hline $\begin{array}{l}\text { 14. Have you ever been evicted from a previous residence or lost a } \\
\text { mortgage or faced foreclosure }\end{array}$ & $-0.124^{*}$ & 0.076 & -0.022 & 0.780 \\
\hline 15. Has anyone in your household ever been incarcerated? & $-0.233^{* * *}$ & 0.001 & -0.029 & 0.719 \\
\hline
\end{tabular}


Table 9. Correlations between the child's answers to survey questions and the child's disciplinary referrals

Please check the box that best describes how often each statement is true for you. Choose only one answer for each statement (1. Never, 2. Seldom,

3. Farly Often, 4. Usually, 5. Always)

Child's disciplinary referrals

$(\mathrm{N}=103)$

Child survey question

p-value

a. I pay attention in class.

0.011

b. I feel happy in school.

c. I would rather do easy work than hard work.

0.014

d. When I am in class, I just act as if I am working.

0.643

e. I feel bored in school.

f. When work is hard, I either give up or do the easy parts.

$-0.243^{* *}$

0.523

0.046

$0.084 \quad 0.400$

g. I complete my homework on time.

h. I find myself focusing so hard at school that time passes quickly.

$0.304^{* * *}$

0.002

$-0.124$

0.219

i. I come to class without the things I need to do my work.

$-0.203^{* *}$

0.046

j. I feel excited by the work in school.

0.012

0.906

j. I feel excited by the work in school.

$-0.063$

0.528

I have to do.

1. I follow the rules at school.

$-0.125$

0.217

m. I like being at school.

$-0.310^{* * *} \quad 0.002$

n. I talk with people outside of school about what I am learning in class.

o. I get in trouble at school.

$-0.061 \quad 0.542$

p. I feel frustrated in school.

$0.186^{*} \quad 0.062$

$0.193^{*} \quad 0.054$

q. I don't try very hard in school.

$0.082 \quad 0.417$

r. I like schoolwork best when it is the same as what we have done

0.032

0.750

before.

s. I am interested in the work at school.

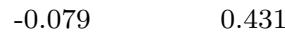

t. I like schoolwork best when it is hard.

0.326

u. My classroom is a fun place to be.

$-0.098$

0.610 
Table 10. Marginal effects of changes in the discount rate and academic achievement on graduating high school in four years

(for a Black boy eligible for free \& reduced price lunch, w/o disciplinary referrals)

\begin{tabular}{lccc} 
& Marginal & s.e. & p-value \\
\hline & & & \\
$\Delta($ d.r. $)=1$ if achievement $=q_{0.1}$ & -0.094 & 0.050 & 0.059 \\
$\Delta($ d.r. $)=1$ if achievement $=q_{0.5}$ & -0.087 & 0.047 & 0.064 \\
$\Delta($ d.r. $)=1$ if achievement $=q_{0.9}$ & -0.043 & 0.029 & 0.138 \\
$\Delta($ achievement $)=q_{0.1}-q_{0.9}$ if d.r. $=0.2$ & 0.438 & 0.087 & 0.000 \\
$\Delta($ achievement $)=q_{0.1}-q_{0.9}$ if d.r. $=q_{0.5}$ & 0.475 & 0.078 & 0.000 \\
$\Delta($ achievement $)=q_{0.1}-q_{0.9}$ if d.r. $=1.2$ & 0.506 & 0.070 & 0.000 \\
& & & \\
\hline
\end{tabular}

$\Delta($ d.r. $)=1$ is a change in the discount rate from 0.2 to 1.2 (the child becomes more impatient), which is moving from the 15 th to the 73rd percentile in the discount rate distribution. $\Delta($ achievement $)=q_{0.1}-q_{0.9}$ is a change in academic achievement from being in the lower decile of the distribution to the upper decile (the child increases academic achievement). 
Table 11. Mediated effect of discount rate and past behavioral problems graduation through 9 th grade discipline

(using observations with known graduation outcome and cost to make consistent that is in the lower 95-percentile)

\begin{tabular}{lcccc}
\hline & Average switch & First switch & Last switch & Min. Cost \\
VARIABLES & $(1)$ & $(2)$ & $(3)$ & $(4)$ \\
\hline Discount rate & $-0.027^{* * *}$ & $-0.028^{* * *}$ & $-0.028^{* * *}$ & $-0.027^{* * *}$ \\
s.e. & 0.010 & 0.010 & 0.011 & 0.011 \\
Percent mediated & 0.331 & 0.353 & 0.363 & 0.361 \\
& & & & $-0.059^{* * *}$ \\
Discipline in 7th grade & $-0.056^{* * *}$ & $-0.056^{* * *}$ & $-0.058^{* * *}$ & 0.015 \\
s.e. & 0.015 & 0.015 & 0.015 & 0.428 \\
Percent mediated & 0.409 & 0.416 & 0.424 & \\
\hline
\end{tabular}




\section{Appendix}

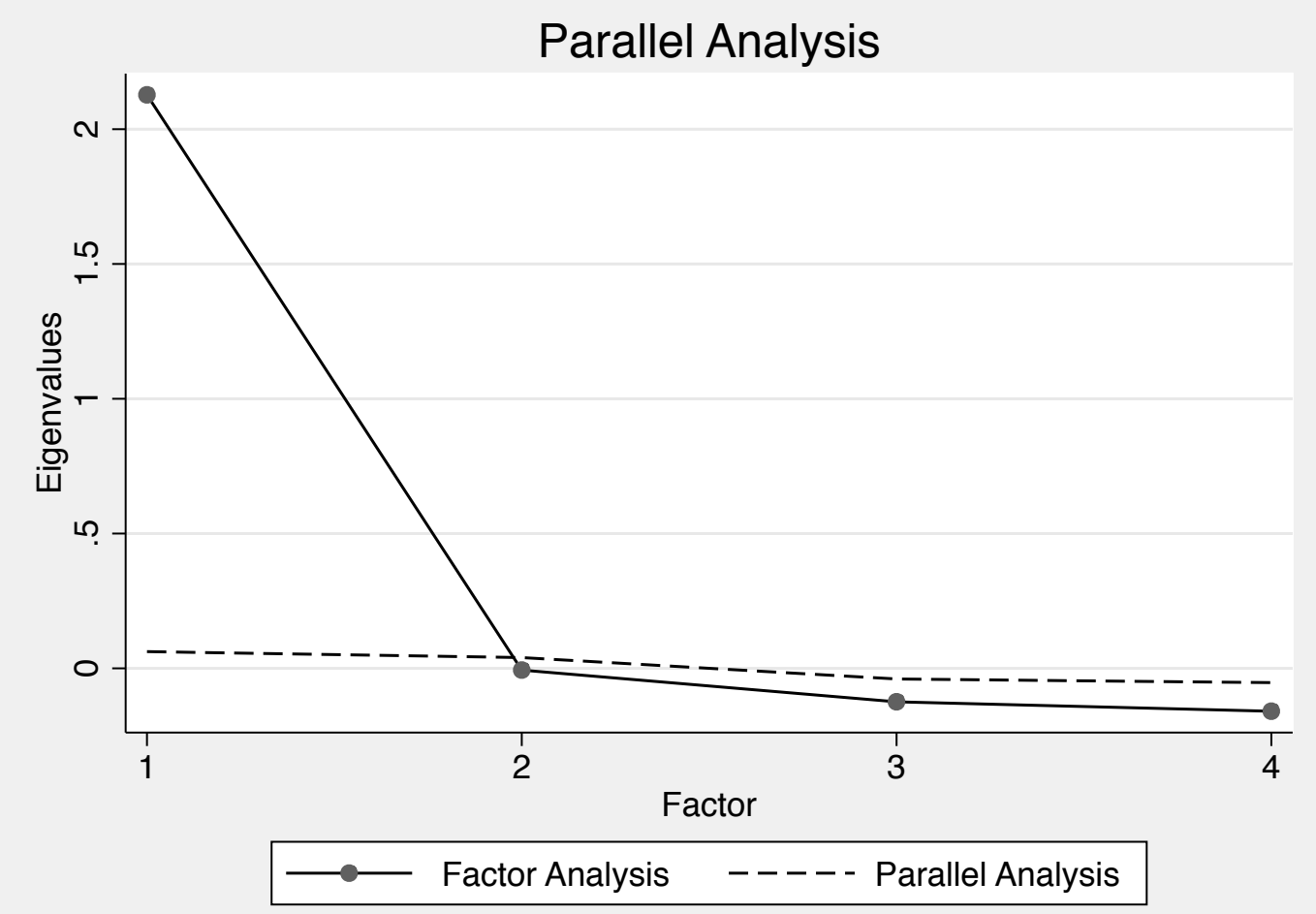

Figure A1: Factor analysis of state level standardized tests in 7th grade: math, reading, social studies and science). 
Table A1. Probit regression on the probability of observing a child's high school graduation outcome

\begin{tabular}{|c|c|}
\hline \multirow[t]{2}{*}{ Disciplinary referrals (7th grade) } & -0.020 \\
\hline & {$[0.015]$} \\
\hline \multirow[t]{2}{*}{ Academic achievement } & $0.493^{* * *}$ \\
\hline & {$[0.092]$} \\
\hline \multirow[t]{2}{*}{ Age } & $-0.221^{* * *}$ \\
\hline & {$[0.080]$} \\
\hline \multirow[t]{2}{*}{ Male } & 0.120 \\
\hline & {$[0.086]$} \\
\hline \multirow[t]{2}{*}{ Black } & $0.406^{* * *}$ \\
\hline & {$[0.105]$} \\
\hline \multirow[t]{2}{*}{ Hispanic \& Multi-racial } & -0.111 \\
\hline & {$[0.214]$} \\
\hline \multirow[t]{2}{*}{ Free \& reduced price meal } & 0.092 \\
\hline & {$[0.108]$} \\
\hline \multirow[t]{2}{*}{ Special education } & $-0.225^{* *}$ \\
\hline & {$[0.100]$} \\
\hline \multirow[t]{2}{*}{ Accumulated credits one year after experiment ${ }^{+}$} & -0.400 \\
\hline & {$[0.345]$} \\
\hline \multirow[t]{2}{*}{ Accumulated credits two years after experiment ${ }^{+}$} & $0.221^{* * *}$ \\
\hline & {$[0.031]$} \\
\hline \multirow[t]{2}{*}{ Value of house $(\text { in } \log )^{+}$} & -0.046 \\
\hline & {$[0.049]$} \\
\hline \multirow[t]{2}{*}{ Filed for homestead exemption ${ }^{+}$} & 0.087 \\
\hline & {$[0.096]$} \\
\hline \multirow[t]{2}{*}{ Two-parent household ${ }^{++}$} & 0.060 \\
\hline & {$[0.121]$} \\
\hline \multirow[t]{2}{*}{ Mother's highest level of education is high school ${ }^{++}$} & -0.146 \\
\hline & {$[0.220]$} \\
\hline \multirow[t]{2}{*}{ Father's highest level of education is high school ${ }^{++}$} & 0.306 \\
\hline & {$[0.313]$} \\
\hline \multirow[t]{2}{*}{ Mother's highest level of education is college ${ }^{++}$} & 0.127 \\
\hline & {$[0.129]$} \\
\hline \multirow[t]{2}{*}{ Father's highest level of education is college ${ }^{++}$} & -0.151 \\
\hline & {$[0.139]$} \\
\hline \multirow[t]{2}{*}{ Household responded to survey request } & $0.251^{* *}$ \\
\hline & {$[0.104]$} \\
\hline Constant & $2.740^{* *}$ \\
\hline
\end{tabular}

$\begin{array}{ll}\text { Constant } & 2.740^{* *}\end{array}$

$[1.335]$

Observations

1,195

Data are from all children who were in the school district in 8th grade in 2006, 2007 and 2008. These children might not have participated in our time preference experiment (e.g. in 2008, we did not collect time preference data from all middle schools.) Pseudo- $\mathrm{R}^{2}=0.2164 .+$ Missing values replaced with 0 and dummy variables added to account for missing data. ++ Missing values replaced with the average at the census track level. Standard errors in brackets. *** $\mathrm{p}<0.01, * * \mathrm{p}<0.05, * \mathrm{p}<0.10$ 
Table A2. Linear probability model of high school graduation in four years (using observations with known graduation outcome and cost to make consistent that is in the lower 95-percentile)

\begin{tabular}{|c|c|c|c|c|}
\hline VARIABLES & $\begin{array}{c}\text { Average switch } \\
\text { (1) }\end{array}$ & $\begin{array}{c}\text { First switch } \\
(2)\end{array}$ & $\begin{array}{c}\text { Last switch } \\
\text { (3) }\end{array}$ & $\begin{array}{c}\text { Min. Cost } \\
(4)\end{array}$ \\
\hline \multirow[t]{3}{*}{ Discount rate } & $-0.073^{*}$ & $-0.069 *$ & $-0.066^{*}$ & -0.065 \\
\hline & {$[0.039]$} & {$[0.039]$} & {$[0.039]$} & {$[0.040]$} \\
\hline & $(0.063)$ & $(0.075)$ & $(0.094)$ & $(0.105)$ \\
\hline \multirow[t]{3}{*}{ Disciplinary referrals ( 7 th grade) } & $-0.027 * * *$ & $-0.026^{* * *}$ & $-0.026^{* * *}$ & $-0.026^{* * *}$ \\
\hline & {$[0.006]$} & {$[0.006]$} & {$[0.006]$} & {$[0.006]$} \\
\hline & $(0.000)$ & $(0.000)$ & $(0.000)$ & $(0.000)$ \\
\hline \multirow[t]{3}{*}{ Academic achievement } & $0.175^{* * *}$ & $0.176^{* * *}$ & $0.172^{* * *}$ & $0.172^{* * *}$ \\
\hline & {$[0.034]$} & {$[0.034]$} & {$[0.033]$} & {$[0.033]$} \\
\hline & $(0.000)$ & $(0.000)$ & $(0.000)$ & $(0.000)$ \\
\hline \multirow[t]{3}{*}{ Age } & $-0.162^{* * *}$ & $-0.163^{* * *}$ & $-0.157^{* * *}$ & $-0.157^{* * *}$ \\
\hline & {$[0.041]$} & {$[0.041]$} & {$[0.041]$} & {$[0.041]$} \\
\hline & $(0.000)$ & $(0.000)$ & $(0.000)$ & $(0.000)$ \\
\hline \multirow[t]{3}{*}{ Male } & $-0.079 * *$ & $-0.081^{* *}$ & $-0.076^{*}$ & $-0.076^{*}$ \\
\hline & {$[0.040]$} & {$[0.040]$} & {$[0.040]$} & {$[0.040]$} \\
\hline & $(0.049)$ & $(0.042)$ & $(0.057)$ & $(0.059)$ \\
\hline \multirow[t]{3}{*}{ Black } & $0.162^{* * *}$ & $0.160^{* * *}$ & $0.168^{* * *}$ & $0.169^{* * *}$ \\
\hline & {$[0.044]$} & {$[0.044]$} & {$[0.044]$} & {$[0.044]$} \\
\hline & $(0.000)$ & $(0.000)$ & $(0.000)$ & $(0.000)$ \\
\hline \multirow[t]{3}{*}{ Hispanic \& Multi-racial } & $0.196^{* *}$ & $0.197^{* *}$ & $0.195^{* *}$ & $0.196^{* *}$ \\
\hline & {$[0.094]$} & {$[0.095]$} & {$[0.094]$} & {$[0.094]$} \\
\hline & $(0.038)$ & $(0.038)$ & $(0.039)$ & $(0.038)$ \\
\hline \multirow[t]{3}{*}{ Free \& reduced price meal } & $-0.122^{* * *}$ & $-0.119 * * *$ & $-0.127^{* * *}$ & $-0.127 * * *$ \\
\hline & {$[0.045]$} & {$[0.044]$} & {$[0.044]$} & {$[0.045]$} \\
\hline & $(0.007)$ & $(0.007)$ & $(0.004)$ & $(0.005)$ \\
\hline \multirow[t]{3}{*}{ Special education } & 0.029 & 0.029 & 0.018 & 0.019 \\
\hline & {$[0.052]$} & {$[0.053]$} & {$[0.054]$} & {$[0.053]$} \\
\hline & $(0.577)$ & $(0.579)$ & $(0.734)$ & $(0.723)$ \\
\hline \multirow[t]{3}{*}{ Constant } & $2.664^{* * *}$ & $2.688^{* * *}$ & $2.432^{* * *}$ & $2.431^{* * *}$ \\
\hline & {$[0.689]$} & {$[0.689]$} & {$[0.678]$} & {$[0.679]$} \\
\hline & $(0.000)$ & $(0.000)$ & $(0.000)$ & $(0.000)$ \\
\hline Observations & 547 & 546 & 545 & 545 \\
\hline R-squared & 0.413 & 0.412 & 0.413 & 0.413 \\
\hline
\end{tabular}

Additional covariates included in regressions but not reported include: dummy for having chosen inconsistently, dummy for homestead exemption filing, house value (in $\log$ ), dummy for two-parent household, dummy for mother's highest educ is high school, dummy for father's highest educ is high school, dummy for mother's highest educ is college, dummy for father's highest educ is college. Missing values replaced with the average at the census track level. Standard errors in brackets, and robust p-values in parentheses. ${ }^{* *} \mathrm{p}<0.01,{ }^{* *} \mathrm{p}<0.05,{ }^{*} \mathrm{p}<0.10$ 
Table A3. Probit regression of high school graduation in four years (marginal effects) (entire sample of children with known graduation outcomes)

\begin{tabular}{|c|c|c|c|c|}
\hline VARIABLES & $\begin{array}{c}\text { Average switch } \\
\text { (1) }\end{array}$ & $\begin{array}{c}\text { First switch } \\
(2)\end{array}$ & $\begin{array}{c}\text { Last switch } \\
\text { (3) }\end{array}$ & $\begin{array}{l}\text { Min. Cost } \\
\text { (4) }\end{array}$ \\
\hline \multirow[t]{3}{*}{ Discount rate } & $-0.087 * *$ & $-0.089 * *$ & $-0.074^{*}$ & $-0.075^{*}$ \\
\hline & {$[0.043]$} & {$[0.039]$} & {$[0.042]$} & {$[0.043]$} \\
\hline & $(0.041)$ & $(0.024)$ & $(0.081)$ & $(0.078)$ \\
\hline \multirow[t]{3}{*}{ Disciplinary referrals (7th grade) } & $-0.025^{* * *}$ & $-0.025^{* * *}$ & $-0.025^{* * *}$ & $-0.025^{* * *}$ \\
\hline & {$[0.006]$} & {$[0.006]$} & {$[0.006]$} & {$[0.006]$} \\
\hline & $(0.000)$ & $(0.000)$ & $(0.000)$ & $(0.000)$ \\
\hline \multirow[t]{3}{*}{ Academic achievement } & $0.229^{* * *}$ & $0.228^{* * *}$ & $0.231^{* * *}$ & $0.231^{* * *}$ \\
\hline & {$[0.042]$} & {$[0.042]$} & {$[0.043]$} & {$[0.043]$} \\
\hline & $(0.000)$ & $(0.000)$ & $(0.000)$ & $(0.000)$ \\
\hline \multirow[t]{3}{*}{ Age } & $-0.155^{* * *}$ & $-0.154^{* * *}$ & $-0.156^{* * *}$ & $-0.156^{* * *}$ \\
\hline & {$[0.035]$} & {$[0.035]$} & {$[0.035]$} & {$[0.035]$} \\
\hline & $(0.000)$ & $(0.000)$ & $(0.000)$ & $(0.000)$ \\
\hline \multirow[t]{3}{*}{ Male } & $-0.072^{*}$ & $-0.074^{*}$ & $-0.072^{*}$ & $-0.072^{*}$ \\
\hline & {$[0.040]$} & {$[0.040]$} & {$[0.040]$} & {$[0.041]$} \\
\hline & $(0.072)$ & $(0.066)$ & $(0.074)$ & $(0.076)$ \\
\hline \multirow[t]{3}{*}{ Black } & $0.169^{* * *}$ & $0.169^{* * *}$ & $0.171^{* * *}$ & $0.170^{* * *}$ \\
\hline & {$[0.043]$} & {$[0.043]$} & {$[0.043]$} & {$[0.043]$} \\
\hline & $(0.000)$ & $(0.000)$ & $(0.000)$ & $(0.000)$ \\
\hline \multirow[t]{3}{*}{ Hispanic \& Multi-racial } & 0.107 & 0.109 & 0.107 & 0.106 \\
\hline & {$[0.089]$} & {$[0.089]$} & {$[0.090]$} & {$[0.089]$} \\
\hline & $(0.230)$ & $(0.221)$ & $(0.231)$ & $(0.234)$ \\
\hline \multirow[t]{3}{*}{ Free \& reduced price meal } & $-0.154^{* * *}$ & $-0.155^{* * *}$ & $-0.153^{* * *}$ & $-0.152^{* * *}$ \\
\hline & {$[0.049]$} & {$[0.049]$} & {$[0.049]$} & {$[0.050]$} \\
\hline & $(0.002)$ & $(0.002)$ & $(0.002)$ & $(0.002)$ \\
\hline \multirow[t]{3}{*}{ Special education } & 0.060 & 0.061 & 0.062 & 0.061 \\
\hline & {$[0.046]$} & {$[0.046]$} & {$[0.047]$} & {$[0.046]$} \\
\hline & $(0.193)$ & $(0.187)$ & $(0.186)$ & $(0.186)$ \\
\hline Observations & 572 & 572 & 572 & 572 \\
\hline \multicolumn{5}{|c|}{$\begin{array}{l}\text { Additional covariates included in regressions but not reported include: dummy for having chosen inconsistently, } \\
\text { dummy for homestead exemption filing, house value (in log), dummy for two-parent household, dummy for mother's } \\
\text { highest educ is high school, dummy for father's highest educ is high school, dummy for mother's highest educ is } \\
\text { college, dummy for father's highest educ is college. Missing values replaced with the average at the census track level. } \\
\text { Standard errors in brackets, and robust p-values in parentheses. }{ }^{* * *} \mathrm{p}<0.01,{ }^{* *} \mathrm{p}<0.05,{ }^{*} \mathrm{p}<0.10\end{array}$} \\
\hline
\end{tabular}


Table A4. Probit regression of high school graduation in four years (marginal effects)

\begin{tabular}{|c|c|c|c|}
\hline & Consistent Sample & & $\begin{array}{l}\text { Sample excluding } \\
\text { those choosing } \\
\text { all patient or all } \\
\text { impatient }\end{array}$ \\
\hline & (1) & $(2)$ & (3) \\
\hline Discount rate & $\begin{array}{c}-0.114^{* * *} \\
{[0.044]} \\
(0.010)\end{array}$ & & \\
\hline Number of impatient decisions & & $\begin{array}{c}-0.007^{* *} \\
{[0.003]} \\
(0.039)\end{array}$ & \\
\hline Discount rate (avg switch) & & & $\begin{array}{l}-0.057 \\
{[0.051]} \\
(0.263)\end{array}$ \\
\hline Disciplinary referrals (7th grade) & $\begin{array}{c}-0.020^{* * *} \\
{[0.006]} \\
(0.002)\end{array}$ & $\begin{array}{c}-0.025^{* * *} \\
{[0.006]} \\
(0.000)\end{array}$ & $\begin{array}{c}-0.025 * * * \\
{[0.007]} \\
(0.000)\end{array}$ \\
\hline Academic achievement & $\begin{array}{c}0.244^{* * *} \\
{[0.049]} \\
(0.000)\end{array}$ & $\begin{array}{c}0.227^{* * *} \\
{[0.042]} \\
(0.000)\end{array}$ & $\begin{array}{c}0.193^{* * *} \\
{[0.041]} \\
(0.000)\end{array}$ \\
\hline Age & $\begin{array}{c}-0.094 * * \\
{[0.041]} \\
(0.022)\end{array}$ & $\begin{array}{c}-0.153^{* * *} \\
{[0.035]} \\
(0.000)\end{array}$ & $\begin{array}{c}-0.117^{* * *} \\
{[0.038]} \\
(0.002)\end{array}$ \\
\hline Male & $\begin{array}{c}-0.106^{* *} \\
{[0.048]} \\
(0.027)\end{array}$ & $\begin{array}{c}-0.074 * \\
{[0.040]} \\
(0.064)\end{array}$ & $\begin{array}{l}-0.040 \\
{[0.042]} \\
(0.340)\end{array}$ \\
\hline Black & $\begin{array}{c}0.185^{* * *} \\
{[0.046]} \\
(0.000)\end{array}$ & $\begin{array}{c}0.171^{* * *} \\
{[0.043]} \\
(0.000)\end{array}$ & $\begin{array}{c}0.184^{* * *} \\
{[0.043]} \\
(0.000)\end{array}$ \\
\hline Hispanic \& Multi-racial & $\begin{array}{c}0.064 \\
{[0.093]} \\
(0.492)\end{array}$ & $\begin{array}{c}0.108 \\
{[0.089]} \\
(0.225)\end{array}$ & $\begin{array}{c}0.131 \\
{[0.081]} \\
(0.106)\end{array}$ \\
\hline Free \& reduced price meal & $\begin{array}{l}-0.093 \\
{[0.058]} \\
(0.110)\end{array}$ & $\begin{array}{c}-0.155^{* * *} \\
{[0.049]} \\
(0.002)\end{array}$ & $\begin{array}{c}-0.154 * * * \\
{[0.051]} \\
(0.003)\end{array}$ \\
\hline Special education & $\begin{array}{c}0.044 \\
{[0.053]} \\
(0.404)\end{array}$ & $\begin{array}{c}0.059 \\
{[0.047]} \\
(0.206)\end{array}$ & $\begin{array}{c}0.057 \\
{[0.048]} \\
(0.230)\end{array}$ \\
\hline Observations & 410 & 572 & 456 \\
\hline
\end{tabular}

Additional covariates included in regressions but not reported include: dummy for having chosen inconsistently, dummy for homestead exemption filing, house value (in log), dummy for two-parent household, dummy for mother's highest educ is high school, dummy for father's highest educ is high school, dummy for mother's highest educ is college, dummy for father's highest educ is college. Missing values replaced with the average at the census track level. Standard errors in brackets, and robust p-values in parentheses. $* * * \mathrm{p}<0.01, * * \mathrm{p}<0.05,{ }^{*} \mathrm{p}<0.10$ 
Table A5. Probit regression of high school graduation in four years (marginal effects) (outcome imputed for missing records, using observations with cost to make consistent that is in the lower 95-percentile)

\begin{tabular}{|c|c|c|c|c|}
\hline VARIABLES & $\begin{array}{c}\text { Average switch } \\
\text { (1) }\end{array}$ & $\begin{array}{c}\text { First switch } \\
(2)\end{array}$ & $\begin{array}{c}\text { Last switch } \\
\text { (3) }\end{array}$ & $\begin{array}{l}\text { Min. Cost } \\
\text { (4) }\end{array}$ \\
\hline \multirow[t]{3}{*}{ Discount rate } & $-0.056^{*}$ & $-0.055^{*}$ & -0.052 & -0.051 \\
\hline & {$[0.033]$} & {$[0.032]$} & {$[0.033]$} & {$[0.034]$} \\
\hline & $(0.088)$ & $(0.089)$ & $(0.117)$ & $(0.130)$ \\
\hline \multirow[t]{3}{*}{ Disciplinary referrals (7th grade) } & $-0.025^{* * *}$ & $-0.024 * * *$ & $-0.024 * * *$ & $-0.024 * * *$ \\
\hline & {$[0.006]$} & {$[0.006]$} & {$[0.005]$} & {$[0.005]$} \\
\hline & $(0.000)$ & $(0.000)$ & $(0.000)$ & $(0.000)$ \\
\hline \multirow[t]{3}{*}{ Academic achievement } & $0.190^{* * *}$ & $0.190^{* * *}$ & $0.185^{* * *}$ & $0.185^{* * *}$ \\
\hline & {$[0.035]$} & {$[0.035]$} & {$[0.035]$} & {$[0.035]$} \\
\hline & $(0.000)$ & $(0.000)$ & $(0.000)$ & $(0.000)$ \\
\hline \multirow[t]{3}{*}{ Age } & $-0.052^{*}$ & $-0.053^{*}$ & $-0.050^{*}$ & $-0.051^{*}$ \\
\hline & {$[0.030]$} & {$[0.030]$} & {$[0.030]$} & {$[0.030]$} \\
\hline & $(0.088)$ & $(0.082)$ & $(0.097)$ & $(0.094)$ \\
\hline \multirow[t]{3}{*}{ Male } & $-0.077^{* *}$ & $-0.079 * *$ & $-0.079 * *$ & $-0.080 * *$ \\
\hline & {$[0.033]$} & {$[0.033]$} & {$[0.033]$} & {$[0.033]$} \\
\hline & $(0.020)$ & $(0.016)$ & $(0.017)$ & $(0.015)$ \\
\hline \multirow[t]{3}{*}{ Black } & $0.118^{* * *}$ & $0.113^{* * *}$ & $0.115^{* * *}$ & $0.118^{* * *}$ \\
\hline & {$[0.039]$} & {$[0.039]$} & {$[0.039]$} & {$[0.039]$} \\
\hline & $(0.002)$ & $(0.003)$ & $(0.003)$ & $(0.002)$ \\
\hline \multirow[t]{3}{*}{ Hispanic \& Multi-racial } & 0.073 & 0.070 & 0.076 & 0.077 \\
\hline & {$[0.079]$} & {$[0.079]$} & {$[0.077]$} & {$[0.077]$} \\
\hline & $(0.356)$ & $(0.375)$ & $(0.324)$ & $(0.320)$ \\
\hline \multirow[t]{3}{*}{ Free \& reduced price meal } & $-0.123^{* * *}$ & $-0.118^{* * *}$ & $-0.121^{* * *}$ & $-0.120^{* * *}$ \\
\hline & {$[0.039]$} & {$[0.039]$} & {$[0.039]$} & {$[0.039]$} \\
\hline & $(0.002)$ & $(0.002)$ & $(0.002)$ & $(0.002)$ \\
\hline \multirow[t]{3}{*}{ Special education } & -0.038 & -0.040 & -0.044 & -0.043 \\
\hline & {$[0.039]$} & {$[0.039]$} & {$[0.039]$} & {$[0.039]$} \\
\hline & $(0.330)$ & $(0.310)$ & $(0.266)$ & $(0.278)$ \\
\hline Observations & 782 & 780 & 780 & 781 \\
\hline
\end{tabular}

Additional covariates included in regressions but not reported include: dummy for having chosen inconsistently, dummy for homestead exemption filing, house value (in log), dummy for two-parent household, dummy for mother's highest educ is high school, dummy for father's highest educ is high school, dummy for mother's highest educ is college, dummy for father's highest educ is college. Missing values replaced with the average at the census track level. Standard errors in brackets, and robust p-values in parentheses. ${ }^{* * *} \mathrm{p}<0.01,{ }^{* *} \mathrm{p}<0.05,{ }^{*} \mathrm{p}<0.10$ 
Table A6. Probit regression on high school graduation in four years using dummy variables for each decision rather than the discount rate (marginal effects)

\begin{tabular}{|c|c|c|c|c|}
\hline & Average switch & First switch & Last switch & Min. Cost \\
\hline \multicolumn{5}{|c|}{ Joint hypothesis that all dummies are significant } \\
\hline$\chi^{2}$-test & 1760.04 & 873.20 & 16261.75 & 8131.69 \\
\hline p-value & 0.000 & 0.000 & 0.000 & 0.000 \\
\hline \multirow[t]{3}{*}{ Disciplinary referrals (7th grade) } & $-0.018^{* * *}$ & $-0.020 * * *$ & $-0.012^{* * *}$ & $-0.014^{* * *}$ \\
\hline & {$[0.004]$} & {$[0.005]$} & {$[0.003]$} & {$[0.003]$} \\
\hline & $(0.000)$ & $(0.000)$ & $(0.000)$ & $(0.000)$ \\
\hline \multirow[t]{3}{*}{ Academic achievement } & $0.119^{* * *}$ & $0.178^{* * *}$ & $0.079 * * *$ & $0.098^{* * *}$ \\
\hline & {$[0.025]$} & {$[0.034]$} & {$[0.016]$} & {$[0.020]$} \\
\hline & $(0.000)$ & $(0.000)$ & $(0.000)$ & $(0.000)$ \\
\hline \multirow[t]{3}{*}{ Age } & $-0.096^{* * *}$ & $-0.126^{* * *}$ & $-0.061 * * *$ & $-0.072^{* * *}$ \\
\hline & {$[0.023]$} & {$[0.031]$} & {$[0.015]$} & {$[0.018]$} \\
\hline & $(0.000)$ & $(0.000)$ & $(0.000)$ & $(0.000)$ \\
\hline \multirow[t]{3}{*}{ Male } & $-0.059 * *$ & $-0.063^{*}$ & $-0.037 * *$ & $-0.044^{* *}$ \\
\hline & {$[0.027]$} & {$[0.034]$} & {$[0.017]$} & {$[0.021]$} \\
\hline & $(0.030)$ & $(0.065)$ & $(0.031)$ & $(0.036)$ \\
\hline \multirow[t]{3}{*}{ Black } & $0.144^{* * *}$ & $0.157 * * *$ & $0.096^{* * *}$ & $0.111^{* * *}$ \\
\hline & {$[0.028]$} & {$[0.035]$} & {$[0.018]$} & {$[0.021]$} \\
\hline & $(0.000)$ & $(0.000)$ & $(0.000)$ & $(0.000)$ \\
\hline \multirow[t]{3}{*}{ Hispanic \& Multi-racial } & 0.059 & 0.078 & 0.032 & 0.040 \\
\hline & {$[0.044]$} & {$[0.060]$} & {$[0.027]$} & {$[0.033]$} \\
\hline & $(0.173)$ & $(0.195)$ & $(0.238)$ & $(0.225)$ \\
\hline \multirow[t]{3}{*}{ Free \& reduced price meal } & $-0.108^{* * *}$ & $-0.145^{* * *}$ & $-0.070^{* * *}$ & $-0.088^{* * *}$ \\
\hline & {$[0.031]$} & {$[0.042]$} & {$[0.020]$} & {$[0.024]$} \\
\hline & $(0.000)$ & $(0.001)$ & $(0.000)$ & $(0.000)$ \\
\hline \multirow[t]{3}{*}{ Special education } & 0.013 & 0.028 & 0.005 & 0.009 \\
\hline & {$[0.029]$} & {$[0.038]$} & {$[0.019]$} & {$[0.023]$} \\
\hline & $(0.644)$ & $(0.465)$ & $(0.802)$ & $(0.682)$ \\
\hline Observations & 545 & 545 & 545 & 545 \\
\hline
\end{tabular}

Additional covariates included in regressions but not reported include: dummy for having chosen inconsistently, dummy for homestead exemption filing, house value (in $\log$ ), dummy for two-parent household, dummy for mother's highest educ is high school, dummy for father's highest educ is high school, dummy for mother's highest educ is college, dummy for father's highest educ is college. Missing values replaced with the average at the census track level. Standard errors in brackets, and robust p-values in parentheses. $* * *$ $\mathrm{p}<0.01,{ }^{* *} \mathrm{p}<0.05, * \mathrm{p}<0.10$ 
Table A7. Probit regression of high school graduation in four years (marginal effects) (using proxy variables for family characteristics, using observations with cost to make consistent that is in the lower 95-percentile)

\begin{tabular}{|c|c|c|c|c|}
\hline VARIABLES & $\begin{array}{c}\text { Average switch } \\
\text { (1) }\end{array}$ & $\begin{array}{c}\text { First switch } \\
(2)\end{array}$ & $\begin{array}{c}\text { Last switch } \\
\text { (3) }\end{array}$ & $\begin{array}{c}\text { Min. Cost } \\
\text { (4) }\end{array}$ \\
\hline \multirow[t]{3}{*}{ Discount rate } & $-0.081^{* *}$ & $-0.076^{*}$ & $-0.073^{*}$ & $-0.070^{*}$ \\
\hline & {$[0.041]$} & {$[0.041]$} & {$[0.041]$} & {$[0.042]$} \\
\hline & $(0.050)$ & $(0.063)$ & $(0.079)$ & $(0.094)$ \\
\hline \multirow[t]{3}{*}{ Disciplinary referrals (7th grade) } & $-0.031^{* * *}$ & $-0.030 * * *$ & $-0.030 * * *$ & $-0.030 * * *$ \\
\hline & {$[0.006]$} & {$[0.006]$} & {$[0.006]$} & {$[0.006]$} \\
\hline & $(0.000)$ & $(0.000)$ & $(0.000)$ & $(0.000)$ \\
\hline \multirow[t]{3}{*}{ Ability } & $0.227 * * *$ & $0.229 * * *$ & $0.220 * * *$ & $0.221 * * *$ \\
\hline & {$[0.044]$} & {$[0.044]$} & {$[0.043]$} & {$[0.044]$} \\
\hline & $(0.000)$ & $(0.000)$ & $(0.000)$ & $(0.000)$ \\
\hline \multirow[t]{3}{*}{ Age } & $-0.134^{* * *}$ & $-0.135^{* * *}$ & $-0.125^{* * *}$ & $-0.126^{* * *}$ \\
\hline & {$[0.036]$} & {$[0.037]$} & {$[0.036]$} & {$[0.036]$} \\
\hline & $(0.000)$ & $(0.000)$ & $(0.000)$ & $(0.000)$ \\
\hline \multirow[t]{3}{*}{ Male } & $-0.108 * *$ & $-0.111^{* *}$ & $-0.102^{* *}$ & $-0.102^{* *}$ \\
\hline & {$[0.044]$} & {$[0.044]$} & {$[0.043]$} & {$[0.043]$} \\
\hline & $(0.013)$ & $(0.011)$ & $(0.019)$ & $(0.019)$ \\
\hline \multirow[t]{3}{*}{ Black } & $0.240^{* * *}$ & $0.238 * * *$ & $0.237^{* * *}$ & $0.239 * * *$ \\
\hline & {$[0.046]$} & {$[0.046]$} & {$[0.044]$} & {$[0.045]$} \\
\hline & $(0.000)$ & $(0.000)$ & $(0.000)$ & $(0.000)$ \\
\hline \multirow[t]{3}{*}{ Hispanic \& Multi-racial } & 0.121 & 0.122 & 0.118 & 0.119 \\
\hline & {$[0.080]$} & {$[0.080]$} & {$[0.078]$} & {$[0.078]$} \\
\hline & $(0.129)$ & $(0.127)$ & $(0.128)$ & $(0.126)$ \\
\hline \multirow[t]{3}{*}{ Free \& reduced price meal } & $-0.189^{* * *}$ & $-0.186^{* * *}$ & $-0.189^{* * *}$ & $-0.190^{* * *}$ \\
\hline & {$[0.052]$} & {$[0.052]$} & {$[0.051]$} & {$[0.051]$} \\
\hline & $(0.000)$ & $(0.000)$ & $(0.000)$ & $(0.000)$ \\
\hline \multirow[t]{3}{*}{ Special education } & 0.064 & 0.065 & 0.053 & 0.053 \\
\hline & {$[0.048]$} & {$[0.048]$} & {$[0.048]$} & {$[0.048]$} \\
\hline & $(0.181)$ & $(0.178)$ & $(0.273)$ & $(0.272)$ \\
\hline \multirow[t]{3}{*}{ Inconsistent } & -0.022 & -0.024 & -0.000 & -0.000 \\
\hline & {$[0.046]$} & {$[0.046]$} & {$[0.046]$} & {$[0.046]$} \\
\hline & $(0.637)$ & $(0.612)$ & $(0.998)$ & $(0.996)$ \\
\hline \multirow[t]{3}{*}{ Filed for homestead exemption } & 0.070 & 0.074 & 0.058 & 0.056 \\
\hline & {$[0.048]$} & {$[0.048]$} & {$[0.047]$} & {$[0.047]$} \\
\hline & $(0.142)$ & $(0.119)$ & $(0.220)$ & $(0.234)$ \\
\hline \multirow[t]{3}{*}{$\log$ of value of house } & 0.025 & 0.022 & 0.050 & 0.051 \\
\hline & {$[0.031]$} & {$[0.031]$} & {$[0.035]$} & {$[0.035]$} \\
\hline & $(0.423)$ & $(0.471)$ & $(0.153)$ & $(0.151)$ \\
\hline \multirow[t]{3}{*}{ Percent of two-parent households } & $0.492^{* *}$ & $0.492^{* *}$ & $0.473^{* *}$ & $0.474^{* *}$ \\
\hline & {$[0.211]$} & {$[0.213]$} & {$[0.210]$} & {$[0.211]$} \\
\hline & $(0.020)$ & $(0.021)$ & $(0.024)$ & $(0.025)$ \\
\hline \multirow[t]{3}{*}{ Percent of women with HS } & -0.193 & -0.188 & -0.197 & -0.202 \\
\hline & {$[0.697]$} & {$[0.699]$} & {$[0.686]$} & {$[0.687]$} \\
\hline & $(0.781)$ & $(0.788)$ & $(0.774)$ & $(0.768)$ \\
\hline \multirow[t]{3}{*}{ Percent of men with HS } & 0.848 & 0.830 & 0.767 & 0.767 \\
\hline & {$[0.578]$} & {$[0.578]$} & {$[0.573]$} & {$[0.574]$} \\
\hline & $(0.142)$ & $(0.151)$ & $(0.181)$ & $(0.181)$ \\
\hline \multirow[t]{3}{*}{ Percent of women with college } & -0.850 & -0.833 & -0.798 & -0.796 \\
\hline & {$[0.942]$} & {$[0.947]$} & {$[0.942]$} & {$[0.942]$} \\
\hline & $(0.367)$ & $(0.379)$ & $(0.397)$ & $(0.398)$ \\
\hline \multirow[t]{3}{*}{ Percent of women with college } & 0.512 & 0.501 & 0.362 & 0.359 \\
\hline & {$[0.965]$} & {$[0.971]$} & {$[0.966]$} & {$[0.966]$} \\
\hline & $(0.596)$ & $(0.606)$ & $(0.708)$ & $(0.710)$ \\
\hline Observations & 538 & 537 & 536 & 536 \\
\hline
\end{tabular}


Table A8. Probit regression of high school graduation in four years (marginal effects). Estimations without using inverse probability weighting. Using proxy variables for family characteristics, using observations with cost to make consistent that is in the lower 95-percentile)

\begin{tabular}{|c|c|c|c|c|}
\hline VARIABLES & $\begin{array}{l}\text { Average switch } \\
\text { (1) }\end{array}$ & $\begin{array}{c}\text { First switch } \\
\text { (2) }\end{array}$ & $\begin{array}{c}\text { Last switch } \\
\text { (3) }\end{array}$ & $\begin{array}{l}\text { Min. Cost } \\
\text { (4) }\end{array}$ \\
\hline \multirow[t]{3}{*}{ Discount rate } & $-0.042^{*}$ & $-0.040^{*}$ & -0.036 & -0.034 \\
\hline & {$[0.023]$} & {$[0.023]$} & {$[0.023]$} & {$[0.023]$} \\
\hline & $(0.067)$ & $(0.078)$ & $(0.118)$ & $(0.143)$ \\
\hline \multirow[t]{3}{*}{ Disciplinary referrals (7th grade) } & $-0.018^{* * *}$ & $-0.018^{* * *}$ & $-0.017^{* * *}$ & $-0.017^{* * *}$ \\
\hline & {$[0.004]$} & {$[0.004]$} & {$[0.004]$} & {$[0.004]$} \\
\hline & $(0.000)$ & $(0.000)$ & $(0.000)$ & $(0.000)$ \\
\hline \multirow[t]{3}{*}{ Ability } & $0.094^{* * *}$ & $0.095^{* * *}$ & $0.091^{* * *}$ & $0.091^{* * *}$ \\
\hline & {$[0.024]$} & {$[0.024]$} & {$[0.023]$} & {$[0.023]$} \\
\hline & $(0.000)$ & $(0.000)$ & $(0.000)$ & $(0.000)$ \\
\hline \multirow[t]{3}{*}{ Age } & $-0.082^{* * *}$ & $-0.082^{* * *}$ & $-0.077^{* * *}$ & $-0.078^{* * *}$ \\
\hline & {$[0.021]$} & {$[0.021]$} & {$[0.021]$} & {$[0.021]$} \\
\hline & $(0.000)$ & $(0.000)$ & $(0.000)$ & $(0.000)$ \\
\hline \multirow[t]{3}{*}{ Male } & $-0.046^{* *}$ & $-0.048^{* *}$ & $-0.044^{*}$ & $-0.044^{*}$ \\
\hline & {$[0.024]$} & {$[0.024]$} & {$[0.023]$} & {$[0.024]$} \\
\hline & $(0.050)$ & $(0.043)$ & $(0.058)$ & $(0.059)$ \\
\hline \multirow[t]{3}{*}{ Black } & $0.139^{* * *}$ & $0.136^{* * *}$ & $0.136^{* * *}$ & $0.137^{* * *}$ \\
\hline & {$[0.028]$} & {$[0.028]$} & {$[0.027]$} & {$[0.027]$} \\
\hline & $(0.000)$ & $(0.000)$ & $(0.000)$ & $(0.000)$ \\
\hline \multirow[t]{3}{*}{ Hispanic \& Multi-racial } & 0.054 & 0.054 & 0.053 & 0.053 \\
\hline & {$[0.046]$} & {$[0.046]$} & {$[0.044]$} & {$[0.044]$} \\
\hline & $(0.240)$ & $(0.243)$ & $(0.237)$ & $(0.235)$ \\
\hline \multirow[t]{3}{*}{ Free \& reduced price meal } & $-0.107^{* * *}$ & $-0.106^{* * *}$ & $-0.108^{* * *}$ & $-0.108^{* * *}$ \\
\hline & {$[0.030]$} & {$[0.030]$} & {$[0.029]$} & {$[0.029]$} \\
\hline & $(0.000)$ & $(0.000)$ & $(0.000)$ & $(0.000)$ \\
\hline \multirow{3}{*}{ Special education } & 0.009 & 0.008 & 0.002 & 0.002 \\
\hline & {$[0.027]$} & {$[0.028]$} & {$[0.028]$} & {$[0.027]$} \\
\hline & $(0.750)$ & $(0.759)$ & $(0.951)$ & $(0.935)$ \\
\hline \multirow[t]{3}{*}{ Inconsistent } & -0.008 & -0.009 & 0.001 & 0.001 \\
\hline & {$[0.025]$} & {$[0.026]$} & {$[0.025]$} & {$[0.025]$} \\
\hline & $(0.743)$ & $(0.718)$ & $(0.973)$ & $(0.961)$ \\
\hline \multirow[t]{3}{*}{ Filed for homestead exemption } & 0.032 & 0.035 & 0.027 & 0.026 \\
\hline & {$[0.026]$} & {$[0.026]$} & {$[0.026]$} & {$[0.026]$} \\
\hline & $(0.221)$ & $(0.189)$ & $(0.306)$ & $(0.321)$ \\
\hline \multirow[t]{3}{*}{$\log$ of value of house } & 0.006 & 0.005 & 0.016 & 0.016 \\
\hline & {$[0.016]$} & {$[0.016]$} & {$[0.017]$} & {$[0.017]$} \\
\hline & $(0.681)$ & $(0.740)$ & $(0.352)$ & $(0.349)$ \\
\hline \multirow[t]{3}{*}{ Percent of two-parent households } & $0.212^{*}$ & $0.211^{*}$ & $0.205^{*}$ & $0.206^{*}$ \\
\hline & {$[0.117]$} & {$[0.118]$} & {$[0.117]$} & {$[0.117]$} \\
\hline & $(0.071)$ & $(0.073)$ & $(0.079)$ & $(0.079)$ \\
\hline \multirow[t]{3}{*}{ Percent of women with HS } & 0.140 & 0.149 & 0.134 & 0.131 \\
\hline & {$[0.359]$} & {$[0.361]$} & {$[0.354]$} & {$[0.354]$} \\
\hline & $(0.696)$ & $(0.680)$ & $(0.706)$ & $(0.711)$ \\
\hline \multirow[t]{3}{*}{ Percent of men with college } & 0.249 & 0.237 & 0.208 & 0.207 \\
\hline & {$[0.315]$} & {$[0.315]$} & {$[0.310]$} & {$[0.310]$} \\
\hline & $(0.429)$ & $(0.453)$ & $(0.503)$ & $(0.505)$ \\
\hline \multirow[t]{3}{*}{ Percent of women with college } & -0.308 & -0.305 & -0.283 & -0.285 \\
\hline & {$[0.494]$} & {$[0.497]$} & {$[0.491]$} & {$[0.490]$} \\
\hline & $(0.533)$ & $(0.539)$ & $(0.564)$ & $(0.561)$ \\
\hline \multirow[t]{3}{*}{ Percent of men with college } & 0.174 & 0.175 & 0.103 & 0.105 \\
\hline & {$[0.507]$} & {$[0.511]$} & {$[0.506]$} & {$[0.506]$} \\
\hline & $(0.732)$ & $(0.732)$ & $(0.839)$ & $(0.835)$ \\
\hline Observations & 538 & 537 & 536 & 536 \\
\hline
\end{tabular}


Table A9. Probit regression of having disciplinary referral in 7th grade (marginal effects)

(using observations with known graduation outcome and cost to make consistent that is in the lower 95-percentile)

\begin{tabular}{|c|c|c|c|c|c|c|c|c|}
\hline \multirow[b]{2}{*}{ VARIABLES } & \multicolumn{2}{|c|}{ Average switch } & \multicolumn{2}{|c|}{ First switch } & \multicolumn{2}{|c|}{ Last switch } & \multicolumn{2}{|c|}{ Min. Cost } \\
\hline & $\begin{array}{l}\text { Inc. } \\
\text { data }\end{array}$ & $\begin{array}{l}\text { Mult. } \\
\text { Imp. }\end{array}$ & $\begin{array}{l}\text { Inc. } \\
\text { data }\end{array}$ & $\begin{array}{l}\text { Mult. } \\
\text { Imp. }\end{array}$ & $\begin{array}{l}\text { Inc. } \\
\text { Data }\end{array}$ & $\begin{array}{l}\text { Mult. } \\
\text { Imp. }\end{array}$ & $\begin{array}{l}\text { Inc. } \\
\text { Data }\end{array}$ & $\begin{array}{l}\text { Mult. } \\
\text { Imp. }\end{array}$ \\
\hline \multirow[t]{3}{*}{ Discount rate } & $-0.331^{*}$ & $-0.351^{* *}$ & $-0.300^{*}$ & $-0.314^{*}$ & $-0.295^{*}$ & $-0.312^{*}$ & -0.284 & $-0.303^{*}$ \\
\hline & {$[0.176]$} & {$[0.177]$} & {$[0.171]$} & {$[0.172]$} & {$[0.176]$} & {$[0.176]$} & {$[0.178]$} & {$[0.178]$} \\
\hline & $(0.060)$ & $(0.048)$ & $(0.079)$ & $(0.068)$ & $(0.093)$ & $(0.076)$ & $(0.110)$ & $(0.088)$ \\
\hline \multirow[t]{3}{*}{1 Safe decision } & $1.578^{*}$ & 0.510 & $1.579^{*}$ & 0.520 & $1.509^{*}$ & 0.504 & $1.511^{*}$ & 0.503 \\
\hline & {$[0.864]$} & {$[0.993]$} & {$[0.861]$} & {$[0.972]$} & {$[0.852]$} & {$[0.949]$} & {$[0.851]$} & {$[0.952]$} \\
\hline & $(0.068)$ & $(0.607)$ & $(0.067)$ & $(0.592)$ & $(0.077)$ & $(0.595)$ & $(0.076)$ & $(0.597)$ \\
\hline \multirow[t]{3}{*}{2 Safe decisions } & $1.165^{*}$ & 0.320 & $1.125^{*}$ & 0.316 & $1.273^{* *}$ & 0.367 & $1.272^{* *}$ & 0.367 \\
\hline & {$[0.642]$} & {$[0.782]$} & {$[0.640]$} & {$[0.760]$} & {$[0.636]$} & {$[0.753]$} & {$[0.637]$} & {$[0.753]$} \\
\hline & $(0.070)$ & $(0.682)$ & $(0.079)$ & $(0.678)$ & $(0.045)$ & $(0.626)$ & $(0.046)$ & $(0.627)$ \\
\hline \multirow[t]{3}{*}{3 Safe decisions } & $1.195^{* *}$ & 0.368 & $1.172^{*}$ & 0.369 & $1.158^{*}$ & 0.367 & $1.155^{*}$ & 0.366 \\
\hline & {$[0.606]$} & {$[0.805]$} & {$[0.603]$} & {$[0.788]$} & {$[0.601]$} & {$[0.782]$} & {$[0.601]$} & {$[0.782]$} \\
\hline & $(0.049)$ & $(0.647)$ & $(0.052)$ & $(0.640)$ & $(0.054)$ & $(0.639)$ & $(0.055)$ & $(0.640)$ \\
\hline \multirow[t]{3}{*}{4 Safe decisions } & $1.845^{* * *}$ & 0.401 & $1.819 * * *$ & 0.403 & $1.772^{* * *}$ & 0.403 & $1.767^{* * *}$ & 0.399 \\
\hline & {$[0.647]$} & {$[0.798]$} & {$[0.642]$} & {$[0.777]$} & {$[0.638]$} & {$[0.775]$} & {$[0.639]$} & {$[0.776]$} \\
\hline & $(0.004)$ & $(0.616)$ & $(0.005)$ & $(0.604)$ & $(0.006)$ & $(0.603)$ & $(0.006)$ & $(0.608)$ \\
\hline \multirow[t]{3}{*}{5 Safe decisions } & 0.816 & 0.318 & 0.821 & 0.331 & 0.780 & 0.324 & 0.778 & 0.322 \\
\hline & {$[0.670]$} & {$[0.863]$} & {$[0.668]$} & {$[0.844]$} & {$[0.664]$} & {$[0.840]$} & {$[0.664]$} & {$[0.841]$} \\
\hline & $(0.224)$ & $(0.712)$ & $(0.219)$ & $(0.695)$ & $(0.240)$ & $(0.700)$ & $(0.241)$ & $(0.701)$ \\
\hline \multirow[t]{3}{*}{ Disciplinary referrals (7th grade) } & $-0.134^{* * *}$ & $-0.128^{* * *}$ & $-0.133^{* * *}$ & $-0.128^{* * *}$ & $-0.136^{* * *}$ & $-0.130^{* * *}$ & $-0.136^{* * *}$ & $-0.131 * * *$ \\
\hline & {$[0.027]$} & {$[0.028]$} & {$[0.027]$} & {$[0.028]$} & {$[0.028]$} & {$[0.029]$} & {$[0.028]$} & {$[0.029]$} \\
\hline & $(0.000)$ & $(0.000)$ & $(0.000)$ & $(0.000)$ & $(0.000)$ & $(0.000)$ & $(0.000)$ & $(0.000)$ \\
\hline \multirow[t]{3}{*}{ Ability } & $1.013^{* * *}$ & $0.982^{* * *}$ & $1.010^{* * *}$ & $0.976^{* * *}$ & $0.975^{* * *}$ & $0.943^{* * *}$ & $0.975^{* * *}$ & $0.942^{* * *}$ \\
\hline & {$[0.194]$} & {$[0.188]$} & {$[0.193]$} & {$[0.187]$} & {$[0.192]$} & {$[0.187]$} & {$[0.193]$} & {$[0.187]$} \\
\hline & $(0.000)$ & $(0.000)$ & $(0.000)$ & $(0.000)$ & $(0.000)$ & $(0.000)$ & $(0.000)$ & $(0.000)$ \\
\hline \multirow[t]{3}{*}{ Age } & $-0.613^{* * *}$ & $-0.575 * * *$ & $-0.631^{* * *}$ & $-0.595 * * *$ & $-0.593^{* * *}$ & $-0.556^{* * *}$ & $-0.593^{* * *}$ & $-0.556^{* * *}$ \\
\hline & {$[0.158]$} & {$[0.158]$} & {$[0.158]$} & {$[0.157]$} & {$[0.158]$} & {$[0.157]$} & {$[0.158]$} & {$[0.157]$} \\
\hline & $(0.000)$ & $(0.000)$ & $(0.000)$ & $(0.000)$ & $(0.000)$ & $(0.000)$ & $(0.000)$ & $(0.000)$ \\
\hline \multirow[t]{3}{*}{ Male } & $-0.392^{* *}$ & $-0.459 * *$ & $-0.394 * *$ & $-0.457^{* *}$ & $-0.371^{* *}$ & $-0.433^{* *}$ & $-0.371^{* *}$ & $-0.432^{* *}$ \\
\hline & {$[0.178]$} & {$[0.184]$} & {$[0.176]$} & {$[0.182]$} & {$[0.178]$} & [0.183] & {$[0.178]$} & {$[0.184]$} \\
\hline & $(0.028)$ & $(0.013)$ & $(0.025)$ & $(0.012)$ & $(0.037)$ & $(0.018)$ & $(0.037)$ & $(0.019)$ \\
\hline \multirow[t]{3}{*}{ Black } & $1.082^{* * *}$ & $1.085^{* * *}$ & $1.071^{* * *}$ & $1.072^{* * *}$ & $1.092^{* * *}$ & $1.097^{* * *}$ & $1.094^{* * *}$ & $1.098^{* * *}$ \\
\hline & {$[0.208]$} & {$[0.217]$} & {$[0.208]$} & {$[0.216]$} & {$[0.208]$} & {$[0.214]$} & {$[0.207]$} & {$[0.214]$} \\
\hline & $(0.000)$ & $(0.000)$ & $(0.000)$ & $(0.000)$ & $(0.000)$ & $(0.000)$ & $(0.000)$ & $(0.000)$ \\
\hline \multirow[t]{3}{*}{ Hispanic \& Multi-racial } & $0.789^{*}$ & 0.805 & 0.785 & 0.794 & $0.793^{*}$ & 0.788 & $0.795^{*}$ & 0.791 \\
\hline & {$[0.477]$} & {$[0.502]$} & {$[0.478]$} & {$[0.502]$} & {$[0.473]$} & {$[0.499]$} & {$[0.471]$} & {$[0.498]$} \\
\hline & $(0.098)$ & $(0.109)$ & $(0.101)$ & $(0.114)$ & $(0.094)$ & $(0.114)$ & $(0.092)$ & $(0.112)$ \\
\hline \multirow[t]{3}{*}{ Free \& reduced price meal } & $-0.876 * * *$ & $-0.950 * * *$ & $-0.870^{* * *}$ & $-0.941 * * *$ & $-0.916^{* * *}$ & $-0.983^{* * *}$ & $-0.917 * * *$ & $-0.984^{* * *}$ \\
\hline & {$[0.257]$} & {$[0.260]$} & {$[0.253]$} & {$[0.256]$} & {$[0.255]$} & {$[0.257]$} & {$[0.255]$} & {$[0.257]$} \\
\hline & $(0.001)$ & $(0.000)$ & $(0.001)$ & $(0.000)$ & $(0.000)$ & $(0.000)$ & $(0.000)$ & $(0.000)$ \\
\hline
\end{tabular}

Additional covariates not shown 
Table A10. Probit regression of disciplinary referral in 7 th grade (marginal effects) (using observations with known graduation outcome and cost to make consistent that is in the lower 95-percentile)

\begin{tabular}{|c|c|c|c|c|}
\hline VARIABLES & $\begin{array}{c}\text { Average switch } \\
\text { (1) }\end{array}$ & $\begin{array}{c}\text { First switch } \\
(2)\end{array}$ & $\begin{array}{c}\text { Last switch } \\
\text { (3) }\end{array}$ & $\begin{array}{l}\text { Min. Cost } \\
\text { (4) }\end{array}$ \\
\hline \multirow[t]{3}{*}{ Discount rate } & -0.025 & -0.012 & -0.042 & -0.042 \\
\hline & {$[0.040]$} & {$[0.040]$} & {$[0.041]$} & {$[0.041]$} \\
\hline & $(0.543)$ & $(0.772)$ & $(0.307)$ & $(0.304)$ \\
\hline \multirow[t]{3}{*}{ Ability } & $-0.193^{* * *}$ & $-0.187^{* * *}$ & $-0.197^{* * *}$ & $-0.198 * * *$ \\
\hline & {$[0.038]$} & {$[0.038]$} & {$[0.038]$} & {$[0.038]$} \\
\hline & $(0.000)$ & $(0.000)$ & $(0.000)$ & $(0.000)$ \\
\hline \multirow[t]{3}{*}{ Age } & 0.041 & 0.041 & 0.044 & 0.045 \\
\hline & {$[0.040]$} & {$[0.040]$} & {$[0.040]$} & {$[0.040]$} \\
\hline & $(0.301)$ & $(0.305)$ & $(0.275)$ & $(0.264)$ \\
\hline \multirow[t]{3}{*}{ Male } & $0.181^{* * *}$ & $0.181^{* * *}$ & $0.188^{* * *}$ & $0.190^{* * *}$ \\
\hline & {$[0.039]$} & {$[0.039]$} & {$[0.039]$} & {$[0.039]$} \\
\hline & $(0.000)$ & $(0.000)$ & $(0.000)$ & $(0.000)$ \\
\hline \multirow[t]{3}{*}{ Black } & $0.089^{*}$ & $0.094^{* *}$ & $0.098 * *$ & $0.094^{* *}$ \\
\hline & {$[0.046]$} & {$[0.046]$} & {$[0.046]$} & {$[0.046]$} \\
\hline & $(0.053)$ & $(0.041)$ & $(0.033)$ & $(0.042)$ \\
\hline \multirow[t]{3}{*}{ Hispanic \& Multi-racial } & -0.048 & -0.048 & -0.053 & -0.056 \\
\hline & {$[0.097]$} & {$[0.096]$} & {$[0.096]$} & {$[0.096]$} \\
\hline & $(0.618)$ & $(0.621)$ & $(0.578)$ & $(0.557)$ \\
\hline \multirow[t]{3}{*}{ Free \& reduced price meal } & $0.112^{* *}$ & $0.112^{* *}$ & $0.119^{* *}$ & $0.118^{* *}$ \\
\hline & {$[0.048]$} & {$[0.048]$} & {$[0.048]$} & {$[0.048]$} \\
\hline & $(0.019)$ & $(0.018)$ & $(0.013)$ & $(0.013)$ \\
\hline \multirow[t]{4}{*}{ Special education } & 0.011 & 0.017 & 0.022 & 0.017 \\
\hline & {$[0.050]$} & {$[0.050]$} & {$[0.051]$} & {$[0.050]$} \\
\hline & $(0.832)$ & $(0.733)$ & $(0.666)$ & $(0.734)$ \\
\hline & \multicolumn{4}{|c|}{ Additional covariates not shown } \\
\hline Observations & 790 & 788 & 788 & 789 \\
\hline
\end{tabular}

Robust s.e. in brackets, p-values in parentheses

$* * * \mathrm{p}<0.01, * * \mathrm{p}<0.05, * \mathrm{p}<0.10$ 
Table A11. Probit regression of high school graduation in four years (marginal effects) (using observations with known graduation outcome and cost to make consistent that is in the lower 95-percentile)

\begin{tabular}{|c|c|c|c|c|}
\hline VARIABLES & $\begin{array}{c}\text { Average switch } \\
\text { (1) }\end{array}$ & $\begin{array}{c}\text { First switch } \\
(2)\end{array}$ & $\begin{array}{c}\text { Last switch } \\
\text { (3) }\end{array}$ & $\begin{array}{c}\text { Min. Cost } \\
\text { (4) }\end{array}$ \\
\hline \multirow[t]{3}{*}{ Discount rate } & $-0.082^{* *}$ & $-0.078^{*}$ & $-0.076^{*}$ & $-0.075^{*}$ \\
\hline & {$[0.041]$} & {$[0.040]$} & {$[0.041]$} & {$[0.042]$} \\
\hline & $(0.045)$ & $(0.051)$ & $(0.065)$ & $(0.071)$ \\
\hline \multirow[t]{3}{*}{ Had disciplinary referral in 7 th } & $-0.137 * * *$ & $-0.134^{* * *}$ & $-0.138 * * *$ & $-0.138^{* * *}$ \\
\hline & {$[0.044]$} & {$[0.044]$} & {$[0.043]$} & {$[0.043]$} \\
\hline & $(0.002)$ & $(0.002)$ & $(0.001)$ & $(0.001)$ \\
\hline \multirow[t]{3}{*}{ Ability } & $0.235^{* * *}$ & $0.236^{* * *}$ & $0.231^{* * *}$ & $0.231^{* * *}$ \\
\hline & {$[0.044]$} & {$[0.044]$} & {$[0.044]$} & {$[0.044]$} \\
\hline & $(0.000)$ & $(0.000)$ & $(0.000)$ & $(0.000)$ \\
\hline \multirow[t]{3}{*}{ Age } & $-0.159 * * *$ & $-0.160 * * *$ & $-0.151^{* * *}$ & $-0.152^{* * *}$ \\
\hline & {$[0.036]$} & {$[0.036]$} & {$[0.036]$} & {$[0.036]$} \\
\hline & $(0.000)$ & $(0.000)$ & $(0.000)$ & $(0.000)$ \\
\hline \multirow[t]{3}{*}{ Male } & $-0.075^{*}$ & $-0.078^{*}$ & $-0.071^{*}$ & $-0.071^{*}$ \\
\hline & {$[0.041]$} & {$[0.041]$} & {$[0.041]$} & {$[0.041]$} \\
\hline & $(0.069)$ & $(0.061)$ & $(0.085)$ & $(0.087)$ \\
\hline \multirow[t]{3}{*}{ Black } & $0.186^{* * *}$ & $0.184^{* * *}$ & $0.189^{* * *}$ & $0.190^{* * *}$ \\
\hline & {$[0.043]$} & {$[0.043]$} & {$[0.042]$} & {$[0.042]$} \\
\hline & $(0.000)$ & $(0.000)$ & $(0.000)$ & $(0.000)$ \\
\hline \multirow[t]{3}{*}{ Hispanic \& Multi-racial } & 0.118 & 0.119 & 0.116 & 0.116 \\
\hline & {$[0.080]$} & {$[0.080]$} & {$[0.079]$} & {$[0.079]$} \\
\hline & $(0.143)$ & $(0.139)$ & $(0.140)$ & $(0.140)$ \\
\hline \multirow[t]{3}{*}{ Free \& reduced price meal } & $-0.159^{* * *}$ & $-0.157^{* * *}$ & $-0.161 * * *$ & $-0.161^{* * *}$ \\
\hline & {$[0.049]$} & {$[0.049]$} & {$[0.048]$} & {$[0.048]$} \\
\hline & $(0.001)$ & $(0.001)$ & $(0.001)$ & $(0.001)$ \\
\hline \multirow[t]{3}{*}{ Special education } & 0.044 & 0.044 & 0.035 & 0.036 \\
\hline & {$[0.046]$} & {$[0.046]$} & {$[0.045]$} & {$[0.046]$} \\
\hline & $(0.340)$ & $(0.332)$ & $(0.437)$ & $(0.433)$ \\
\hline
\end{tabular}

Additional covariates not shown 
Table A12. Probit regression of disciplinary referrals in 9th (marginal effects)

(using observations with known graduation outcome and cost to make consistent that is in the lower 95-percentile)

\begin{tabular}{|c|c|c|c|c|}
\hline VARIABLES & $\begin{array}{c}\text { Average switch } \\
\text { (1) }\end{array}$ & $\begin{array}{c}\text { First switch } \\
(2)\end{array}$ & $\begin{array}{c}\text { Last switch } \\
\text { (3) }\end{array}$ & $\begin{array}{c}\text { Min. Cost } \\
\text { (4) }\end{array}$ \\
\hline \multirow[t]{3}{*}{ Discount rate } & $0.134^{* * *}$ & $0.135^{* * *}$ & $0.129 * * *$ & $0.126 * * *$ \\
\hline & {$[0.041]$} & {$[0.040]$} & {$[0.041]$} & {$[0.041]$} \\
\hline & $(0.001)$ & $(0.001)$ & $(0.002)$ & $(0.002)$ \\
\hline \multirow[t]{3}{*}{ Had disciplinary referral in 7 th grade } & $0.275^{* * *}$ & $0.275^{* * *}$ & $0.273^{* * *}$ & $0.275^{* * *}$ \\
\hline & {$[0.040]$} & {$[0.040]$} & {$[0.040]$} & {$[0.040]$} \\
\hline & $(0.000)$ & $(0.000)$ & $(0.000)$ & $(0.000)$ \\
\hline \multirow[t]{3}{*}{ Ability } & $-0.183^{* * *}$ & $-0.182^{* * *}$ & $-0.177^{* * *}$ & $-0.177^{* * *}$ \\
\hline & {$[0.042]$} & {$[0.042]$} & {$[0.041]$} & {$[0.041]$} \\
\hline & $(0.000)$ & $(0.000)$ & $(0.000)$ & $(0.000)$ \\
\hline \multirow[t]{3}{*}{ Age } & -0.010 & -0.007 & 0.004 & 0.004 \\
\hline & {$[0.039]$} & {$[0.039]$} & {$[0.039]$} & {$[0.039]$} \\
\hline & $(0.804)$ & $(0.858)$ & $(0.911)$ & $(0.920)$ \\
\hline \multirow[t]{3}{*}{ Male } & $0.097^{* *}$ & $0.094^{* *}$ & $0.090^{* *}$ & $0.093^{* *}$ \\
\hline & {$[0.040]$} & {$[0.040]$} & {$[0.040]$} & {$[0.040]$} \\
\hline & $(0.015)$ & $(0.019)$ & $(0.024)$ & $(0.020)$ \\
\hline \multirow[t]{3}{*}{ Black } & 0.026 & 0.020 & 0.020 & 0.025 \\
\hline & {$[0.047]$} & {$[0.047]$} & {$[0.047]$} & {$[0.047]$} \\
\hline & $(0.575)$ & $(0.667)$ & $(0.666)$ & $(0.600)$ \\
\hline \multirow[t]{3}{*}{ Hispanic \& Multi-racial } & -0.048 & -0.053 & -0.061 & -0.057 \\
\hline & {$[0.103]$} & {$[0.103]$} & {$[0.102]$} & {$[0.103]$} \\
\hline & $(0.643)$ & $(0.611)$ & $(0.549)$ & $(0.575)$ \\
\hline \multirow[t]{3}{*}{ Free \& reduced price meal } & $0.123^{* *}$ & $0.124^{* *}$ & $0.122^{* *}$ & $0.115^{* *}$ \\
\hline & {$[0.049]$} & {$[0.049]$} & {$[0.049]$} & {$[0.049]$} \\
\hline & $(0.012)$ & $(0.011)$ & $(0.013)$ & $(0.019)$ \\
\hline \multirow[t]{3}{*}{ Special education } & 0.064 & 0.061 & 0.075 & 0.079 \\
\hline & {$[0.050]$} & {$[0.050]$} & {$[0.050]$} & {$[0.050]$} \\
\hline & $(0.202)$ & $(0.226)$ & $(0.138)$ & $(0.118)$ \\
\hline
\end{tabular}

Additional covariates not shown

\begin{tabular}{llllll} 
Observations & 790 & 788 & 788 & 789 \\
\hline
\end{tabular}

Robust s.e. in brackets, p-values in parentheses

$$
\text { *** } \mathrm{p}<0.01, * * \mathrm{p}<0.05,{ }^{*} \mathrm{p}<0.10
$$


Table A13. Probit regression of high school graduation in four years (marginal effects) - controlling for intermediate outcomes

(using observations with known graduation outcome and cost to make consistent that is in the lower 95-percentile)

\begin{tabular}{|c|c|c|c|c|}
\hline VARIABLES & $\begin{array}{c}\text { Average switch } \\
\text { (1) }\end{array}$ & $\begin{array}{c}\text { First switch } \\
(2)\end{array}$ & $\begin{array}{c}\text { Last switch } \\
\text { (3) }\end{array}$ & $\begin{array}{c}\text { Min. Cost } \\
\text { (4) }\end{array}$ \\
\hline \multirow[t]{3}{*}{ D.R. } & -0.048 & -0.046 & -0.041 & -0.040 \\
\hline & {$[0.041]$} & {$[0.040]$} & {$[0.041]$} & {$[0.041]$} \\
\hline & $(0.238)$ & $(0.247)$ & $(0.315)$ & $(0.327)$ \\
\hline \multirow[t]{3}{*}{ Had disciplinary referral in 7 th grade } & $-0.077^{*}$ & $-0.075^{*}$ & $-0.071^{*}$ & $-0.070^{*}$ \\
\hline & {$[0.043]$} & {$[0.043]$} & {$[0.042]$} & {$[0.042]$} \\
\hline & $(0.072)$ & $(0.081)$ & $(0.090)$ & $(0.094)$ \\
\hline \multirow[t]{3}{*}{ Had disciplinary referral in 9 th grade } & $-0.203^{* * *}$ & $-0.203^{* * *}$ & $-0.214^{* * *}$ & $-0.215^{* * *}$ \\
\hline & {$[0.045]$} & {$[0.045]$} & {$[0.045]$} & {$[0.045]$} \\
\hline & $(0.000)$ & $(0.000)$ & $(0.000)$ & $(0.000)$ \\
\hline \multirow[t]{3}{*}{ Ability } & $0.192^{* * *}$ & $0.193^{* * *}$ & $0.186^{* * *}$ & $0.186^{* * *}$ \\
\hline & {$[0.041]$} & {$[0.041]$} & {$[0.040]$} & {$[0.041]$} \\
\hline & $(0.000)$ & $(0.000)$ & $(0.000)$ & $(0.000)$ \\
\hline \multirow[t]{3}{*}{ Age } & $-0.146 * * *$ & $-0.146 * * *$ & $-0.135 * * *$ & $-0.135^{* * *}$ \\
\hline & {$[0.034]$} & {$[0.034]$} & {$[0.033]$} & {$[0.033]$} \\
\hline & $(0.000)$ & $(0.000)$ & $(0.000)$ & $(0.000)$ \\
\hline \multirow[t]{3}{*}{ Male } & -0.063 & -0.065 & -0.065 & -0.065 \\
\hline & {$[0.040]$} & {$[0.040]$} & {$[0.040]$} & {$[0.040]$} \\
\hline & $(0.119)$ & $(0.106)$ & $(0.108)$ & $(0.109)$ \\
\hline \multirow[t]{3}{*}{ Black } & $0.204^{* * *}$ & $0.201^{* * *}$ & $0.208 * * *$ & $0.209 * * *$ \\
\hline & {$[0.044]$} & {$[0.043]$} & {$[0.043]$} & {$[0.043]$} \\
\hline & $(0.000)$ & $(0.000)$ & $(0.000)$ & $(0.000)$ \\
\hline \multirow[t]{3}{*}{ Hispanic \& Multi-racial } & 0.116 & 0.116 & 0.115 & 0.115 \\
\hline & {$[0.079]$} & {$[0.079]$} & {$[0.077]$} & {$[0.077]$} \\
\hline & $(0.139)$ & $(0.138)$ & $(0.134)$ & $(0.133)$ \\
\hline \multirow[t]{3}{*}{ Free \& reduced price meal } & $-0.137^{* * *}$ & $-0.135 * * *$ & $-0.139 * * *$ & $-0.140^{* * *}$ \\
\hline & {$[0.048]$} & {$[0.048]$} & {$[0.047]$} & {$[0.047]$} \\
\hline & $(0.005)$ & $(0.005)$ & $(0.003)$ & $(0.003)$ \\
\hline \multirow[t]{3}{*}{ Special education } & 0.053 & 0.053 & 0.049 & 0.050 \\
\hline & {$[0.044]$} & {$[0.044]$} & {$[0.044]$} & {$[0.044]$} \\
\hline & $(0.225)$ & $(0.224)$ & $(0.260)$ & $(0.256)$ \\
\hline
\end{tabular}

Additional covariates not shown

Observations

547

546

545

545

Robust s.e. in brackets, p-values in parentheses

${ }^{* * *} \mathrm{p}<0.01,{ }^{* *} \mathrm{p}<0.05,{ }^{*} \mathrm{p}<0.10$ 